This is the post print version of the article, which has been published in Pediatric Obesity. 2017, 12 (Supplement S1), 26-37. http://dx.doi.org/10.1111/ijpo.12170.

\title{
Maternal fatty acid intake during pregnancy and the development of childhood overweight: a birth cohort study
}

Leena Hakola $^{1}$, Hanna-Mari Takkinen ${ }^{1,2}$, Sari Niinistö ${ }^{2}$, Suvi Ahonen ${ }^{1,2,3}$, Iris Erlund ${ }^{2}$, Jenna Rautanen $^{2}$, Riitta Veijola ${ }^{4}$, Jorma Ilonen ${ }^{5}$, Jorma Toppari ${ }^{6,7}$, Mikael Knip ${ }^{8,9,10,11}$, Suvi M. Virtanen $^{1,2,3,11}$ Susanna Lehtinen-Jacks ${ }^{1,2}$

${ }^{1}$ School of Health Sciences, University of Tampere, Tampere, Finland

${ }^{2}$ Department of Health, National Institute for Health and Welfare, Helsinki, Finland

${ }^{3}$ The Science Center of Pirkanmaa Hospital District, Tampere; Finland

${ }^{4}$ Department of Pediatrics, PEDEGO Research Unit, Medical Research Center Oulu, University of Oulu and Oulu University Hospital, Oulu, Finland

${ }^{5}$ Immunogenetics Laboratory, University of Turku and Turku University Hospital, Turku, Finland

${ }^{6}$ Department of Physiology, Institute of Biomedicine, University of Turku, Turku, Finland

${ }^{7}$ Department of Pediatrics, Turku University Hospital, Turku, Finland

${ }^{8}$ Children's Hospital, University of Helsinki and Helsinki University Hospital, Helsinki, Finland

${ }^{9}$ Research Programs Unit, University of Helsinki, Helsinki, Finland

${ }^{10}$ Folkhälsan Research Center, Helsinki, Finland

${ }^{11}$ Center for Child Health Research, University of Tampere and Tampere University Hospital, Tampere, Finland

Keywords: Pregnancy, Fatty Acids, Diet, Children, Overweight, Cohort Studies

Running title: Maternal dietary fatty acids and offspring obesity

Corresponding author: Leena Hakola

School of Health Sciences, FI-33014 University of Tampere, Finland

Email: leena.hakola@uta.fi 


\section{What is already known about this subject?}

- Maternal diet during pregnancy may contribute to the risk of offspring adiposity

- Maternal intake of $n-6$ polyunsaturated fatty acids (PUFAs) during pregnancy has been proposed to contribute to higher offspring adiposity, while intake of $n$-3 polyunsaturated fatty acids has been suggested to contribute to less adiposity

- Limited data from human studies show mixed results and no clear association between maternal fatty acid intake and offspring adiposity

\section{What this study adds?}

- This study adds to the small pool of human studies exploring maternal fatty acid intake during pregnancy and offspring overweight and obesity

- We provide data on maternal intake of several individual fatty acids

- Both low and high maternal intake ratios of n-6:n-3 PUFAs in late pregnancy were associated with an increased risk of later obesity in girls, while a higher intake ratio of arachidonic acid (20:4n-6): docosahexaenoic acid + eicosapentaenoic acid was associated with a decreased risk of obesity in boys. 


\section{Abstract}

Background: Maternal diet during pregnancy may contribute to the risk of offspring adiposity.

Objectives: To explore the associations between maternal antenatal dietary fatty acid intake and the risk of offspring overweight and obesity at the ages of 2 to 7 years.

Methods: In a prospective Finnish birth cohort with 3807 mother-child pairs, maternal diet in late pregnancy was assessed with a food frequency questionnaire. Intakes of total fatty acids and individual saturated (SFAs), monounsaturated (MUFAs), and polyunsaturated fatty acids (PUFAs) were calculated. Generalized estimating equation (GEE) models were used to study the associations of maternal dietary variables with repeatedly measured offspring overweight and obesity.

Results: In girls, maternal intake ratio of $n-6: n-3$ PUFAs had a U-shaped association with obesity (adjusted OR for the lowest 2.0 [95\% CI 1.27-3.20] and the highest 1.7 [1.03-2.73] vs. the two middle quartiles of $n-6: n-3$ PUFAs, $\mathrm{p}=0.01)$. In boys, arachidonic acid (20:4n-6): docosahexaenoic acid + eicosapentaenoic acid ratio was associated with obesity (adjusted OR for the lowest 1.0 [0.60-1.57] and the highest 0.5 [0.26-0.88] vs. the two middle quartiles, $\mathrm{p}=0.02)$. SFAs and MUFAs were not associated with overweight or obesity in either sex.

Conclusions: Maternal intakes of PUFAs in late pregnancy were associated with risk of later obesity differently in girls and boys. 


\section{Abbreviations}

PUFA Polyunsaturated fatty acid

DHA Docosahexaenoic acid

EPA Eicosapentaenoic acid

DIPP study Type 1 Diabetes Prediction and Prevention study

FFQ Food frequency questionnaire

BMI Body mass index

IOTF International Obesity Task Force

WHO World Health Organization

GEE Generalized estimating equations

SFA Saturated fatty acid

MUFA Monounsaturated fatty acid

\section{Introduction}

Intrauterine exposures may contribute to the risk of adiposity later in life by affecting developmental programming (1). Suggested exposures associated with offspring adiposity include maternal nutritional, hormonal, and inflammatory milieus during pregnancy (2-4). Dietary fatty acids and their metabolites work as signaling molecules that may modulate gene expression and protein function on pathways related to energy balance, endocrine responses, and inflammation (5). During pregnancy, maternal fat intake contributes to the fetal fatty acid environment, and may thus contribute to child adiposity (5). It has been suggested that a high intake ratio of $n-6: n-3$ polyunsaturated fatty acids (PUFAs) exaggerates fetal adipose tissue development because $n-6$ and n-3 PUFAs are competitive substrates with partly different adipogenic and inflammatory effects (6).

A few cohort studies have investigated maternal dietary intake or plasma concentrations of fatty acids during pregnancy in relation to offspring adiposity (7-12). In the only study exploring the intake of specific fatty acids, a higher intake of mid-pregnancy $n$-3 long-chain PUFAs (docosahexaenoic acid (DHA) + eicosapentaenoic acid (EPA)) was associated with a lower risk of 
adiposity in 3-year-olds, whereas a higher ratio of $n-6: n-3$ was associated with a higher risk (7). Due to the limited number of studies and mixed results, the role of maternal PUFAs on offspring adiposity remains unclear (5).

Our aim was to study the associations between maternal late-pregnancy intake of dietary fatty acids, including several individual fatty acids, and the longitudinal development of offspring overweight and obesity between the ages of 2 and 7 years.

\section{Methods}

\section{Study population}

The study is part of the Finnish Type 1 Diabetes Prediction and Prevention (DIPP) study, a large population-based birth cohort study of children with $H L A-D Q B I$-conferred susceptibility to type 1 diabetes (13). At the time of the screening, $99 \%$ of the Finnish population was Caucasian, and children with two non-Caucasian parents, severe diseases, or anomalies were excluded (13). The children participated in follow-up visits, including blood sampling and anthropometric measurements, scheduled for $3,6,12,18$, and 24 months of age, and annually thereafter, until the age of 15 or the onset of type 1 diabetes. Of the 54350 screened children, 7782 infants born in Tampere and Oulu University Hospitals between September 1996 and September 2004 were invited, and finally 6083 were enrolled into the DIPP Nutrition Study (Supplemental Figure S1). Inclusion criteria for the present report were being a singleton and having data for the maternal food frequency questionnaire (FFQ), birth size, and at least one weight and height measurement between 2 and 7 years ( \pm 3 months) of age (Figure S1). Parents gave their written informed consent for genetic testing of the newborn and for participation in the follow-up. The study adheres to the Declaration of Helsinki, and the local ethics committees approved the study protocol.

\section{Maternal nutrition}


The mothers completed a validated 181-item semi-quantitative FFQ concerning their habitual diet during the eighth month of pregnancy, the last month preceding the maternity leave in Finland (14). The questionnaires were mailed to the mothers after delivery and checked at the 3-month visit. The FFQ contained questions on the frequency and amount of foods consumed; fat used in cooking, baking, and salad dressing; the extent of home baking; and the use of dietary supplements. These questions were used to calculate individual nutrient intakes based on the Finnish Food Composition Database (Fineli), and the data were analyzed with the in-house software (Finessi) of the National Institute for Health and Welfare, Finland. Energy from dietary fiber was included in the energy from carbohydrates and in the total energy. FFQs with $>10$ missing items were excluded. The validity and reproducibility of the FFQ data collection after pregnancy to record diet during eight month of pregnancy is generally good (14).

\section{Offspring anthropometrics}

At each visit of a child aged 2 years or older, the body weight was measured using an electronic scale in underwear or light indoor clothing, and the height was measured using a wall-mounted measure with the child barefoot. Body mass index $\left(\mathrm{BMI}, \mathrm{kg} / \mathrm{m}^{2}\right)$ was calculated, and overweight (including obesity) and obesity were defined according to the International Obesity Task Force (IOTF) (15) and World Health Organization (WHO) criteria (16).

\section{Covariates}

Information on the maternal level of education, as well as height, weight, and gestational weeks at the first and last antenatal visits as recorded in the maternity record book was collected using structured questionnaires completed after delivery. Maternal adherence to a glucose intolerance diet was based on the question about the mother's special diet during pregnancy due to disturbances in glucose metabolism (answer: yes/no). Maternal BMI was calculated from the weight at the first 
antenatal visit. The means (standard deviations) of gestational age at the first and the last antenatal visits were 9.6 (2.2) and 38.9 (2.0) weeks, respectively. If the first weight measurement was after 10.0 weeks of gestation, the weight at 10.0 weeks was estimated based on the weight difference between the first and last antenatal visit, assuming linear weight gain during the second and third trimesters of pregnancy (17). Gestational weight gain rate was calculated by dividing the change in weight between the first and the last antenatal visits by the time between measurements in weeks. The duration of any breastfeeding was assessed by a dietary questionnaire up to 2 years. Information on the number of previous deliveries, gestational age, number of fetuses, offspring sex, birth weight and length, maternal age, and smoking during pregnancy was obtained from the birth registers of the hospitals.

\section{Statistical methods}

Differences in baseline characteristics between boys and girls, as well as between included and excluded participants, were tested using the Chi Square and Mann-Whitney $U$ tests. IOTF-defined overweight (including obesity) and obesity were used as binary outcomes (15). We used generalized estimating equation (GEE) models to study the associations of covariates and maternal dietary variables on the repeatedly measured offspring overweight and obesity. An autoregressive working correlation structure was used to model the correlation of the repeated outcomes. Fatty acid variables and fatty acid ratios were energy-adjusted using Willett's residual method (18) after logarithmic transformation. Dietary variables were analyzed as continuous variables and as categorized into quartiles; the two middle quartiles were combined and used as the reference category. The main analyses (using quartile categorization of the exposure variables) were performed separately for boys and girls, and adjusted for maternal BMI, gestational weight gain rate, time of the first weight measurement ( $\leq 10.0$ vs. $>10$ weeks of pregnancy), glucose intolerance diet, education, and smoking during pregnancy, as well as duration of breastfeeding. To test 
whether offspring sex modified the associations between dietary variables and overweight or obesity, we added interaction terms into the models.

We repeated the adjusted main analysis as follows: 1) excluding children who had developed type 1 diabetes $(\mathrm{n}=114)$ or advanced preclinical diabetes (repeated positivity for at least two predefined islet autoantibodies (13) ( $\mathrm{n}=128)$ ) by May or September 2014, respectively; 2) using tertile-based exposures; 3) using WHO-defined outcomes and quartile-based exposures. SAS software version 9.3 (SAS Institute, Cary, NC, USA) was used, and statistical significance was set at $\mathrm{p}<0.05$.

\section{Results}

\section{Characteristics of the study population}

Altogether 3807 mother-child pairs were included in the analyses (Figure S1). The mothers of singletons who were invited to the study but had insufficient data on maternal diet or child growth $(\mathrm{n}=3602)$, were younger, more likely to be smokers, and had a higher number of previous deliveries and a lower level education than those included (19).

The median follow-up time regarding growth was 7 years (interquartile range (IQR): 6-7) and the median number of growth measurements at the age of 2-7 years was 3 (IQR: 2-5) per child. A much higher proportion of children was defined as overweight or obese by the WHO than the IOTF criteria (Figure 1).

In general, higher maternal early pregnancy BMI, gestational weight gain rate, and offspring birth weight, maternal smoking during pregnancy, a lower level of maternal education, and a shorter duration of breastfeeding were associated with an increased odds of offspring overweight or obesity (Table 1). There were no differences between mothers of boys and girls in mean intakes of energy, the contribution of carbohydrates, proteins, and fats to the total energy intake, or the intakes of fatty acids (Table S1, sex-specific data not shown). 
In girls, none of the categorized maternal dietary factors were associated with overweight in the adjusted analysis (Table 2). In boys, higher maternal intake of $n$-6 PUFA was associated with lower adjusted odds of overweight, with borderline significance (Table 2). The unadjusted results are shown in Supplemental Table S2. None of the continuous maternal dietary variables were associated with overweight in boys or girls.

\section{Maternal dietary intake and offspring obesity}

In girls, the lowest and highest quartiles of maternal $n$-3 PUFA intake, $n-6: n-3$ intake ratio, and linoleic acid (18:2n-6): $\alpha$-linolenic acid (18:3n-3) intake ratio were all associated with greater adjusted odds of obesity, compared to the two middle quartiles (Table 2). In boys, maternal intake of EPA and intake ratio of arachidonic acid (20:4n-6):DHA+EPA were associated with obesity, such that the lowest quartile of EPA intake and the highest quartile of arachidonic acid (20:4n6):DHA+EPA intake ratio were associated with lower adjusted odds of obesity (Table 2). The unadjusted results are shown in Table S2. None of the continuous maternal dietary variables were associated with obesity in boys or girls.

\section{Interaction and sensitivity analyses}

The sex of the offspring modified the association between $n-6: n-3$ ratio and obesity, with a U-shaped association in girls and no association in boys (for interaction, $\mathrm{p}=0.04$ ). No other sex interactions were observed.

We excluded children with advanced preclinical or clinical type 1 diabetes. The directions of the associations between the dietary variables and overweight or obesity remained similar to those in the main analyses. However, the association between EPA intake and obesity in boys was no longer statistically significant. 
When using tertile-based exposures, the association between maternal $n-6: n$-3 PUFA intake ratio and obesity in girls was slightly stronger, while the associations between $n$-3 PUFA and linoleic acid (18:2n-6): $\alpha$-linolenic acid (18:3n-3) intake ratio with obesity were weaker (Table S3), compared to quartile-based exposures (Table 2). In boys, the results changed only minimally (Table S3 vs. Table 2).

Finally, when using the WHO-defined overweight and obesity, and quartile-based exposures, the results were slightly weaker but comparable with the main analyses (Supplemental Table S4 vs. Table 2).

\section{Discussion}

In this prospective birth cohort, maternal intake ratio of $n-6: n-3$ PUFAs during late pregnancy exhibited a U-shaped association with obesity in girls aged 2 to 7 years. In boys, maternal intake ratio of arachidonic acid (20:4n-6):DHA+EPA was associated with obesity such that the odds of obesity was lower in the highest vs. the two middle quartiles. These associations were consistent irrespectively of whether using tertile- or quartile-based exposures, or the IOTF or WHO criteria for obesity, and remained significant after adjustment for several putative confounders. In addition, maternal intake of $n$-3 PUFAs and intake ratio of linoleic acid: $\alpha$-linolenic acid had a U-shaped association with obesity in girls, and lowest intake of maternal EPA intake was associated with lower odds of obesity in boys. However, these associations were weaker when using tertile-based exposures, or the WHO criteria for obesity.

To our knowledge, this is the first cohort study reporting associations between maternal antenatal intakes of individual fatty acids other than PUFAs and any measure of offspring adiposity. The major strengths of the current study are related to the large prospective birth cohort setting and the use of a validated FFQ to assess the maternal intake of individual and total fatty acids during late pregnancy. Other strengths include the large number of repeated growth measurements and the 
longitudinal analysis of overweight and obesity. Further, we adjusted the analyses for several potential confounders, including duration of breastfeeding. However, we could not adjust for other items in offspring nutrition, or physical activity. Although the validity of fat and fatty acid intake by FFQ is generally good, it is modest for intakes of oils and low-fat margarines (14). On the other hand, a similar FFQ on lactating women correlates well with infant serum concentrations of saturated fatty acids (SFAs) and n-3 PUFAs, supporting the suitability of the FFQ for assessing the intake of fatty acids (20).

We mainly used the IOTF BMI cut-offs for child overweight and obesity, which are analogous to the widely used adult cut-offs of $25 \mathrm{~kg} / \mathrm{m}^{2}$ and $30 \mathrm{~kg} / \mathrm{m}^{2}$ (15). Although BMI does not separate fat and lean mass, it is accepted as a valid indirect measure of adiposity in children (21) and it strongly predicts cardiometabolic risk factors, including overweight, in adulthood (22). The mothers and their offspring who were invited to the follow-up but did not have FFQ or growth data differed in some aspects from those included in the analysis, which might have caused some selection bias. Finally, we cannot rule out chance findings due to multiple testing. However, the main associations were also seen in the sensitivity analyses.

Our findings of an U-shaped association between maternal n-6:n-3 PUFAs intake ratio and obesity in girls - and no such association in boys - do not fully support the hypothesis that a higher maternal dietary intake ratio of n-6:n-3 PUFAs during pregnancy promotes offspring adiposity (6). Our results partly differ from the only previous comparable cohort study (from the US) that found an inverse association between maternal intake of $n-3$ PUFAs during pregnancy and offspring obesity (BMI) or skinfold thickness, as well as a direct association between the $n-6: n-3$ PUFA ratio and skinfold thickness (borderline significance for obesity), in both sexes together (7). Our observation related to the arachidonic acid:DHA+EPA intake ratio has not been reported before. 
In Finland, the intake of plant $n-3$ PUFAs is among the highest in the world due to the high consumption of canola oil, and the intake of seafood $n$-3 PUFAs is above the global mean as well $(23,24)$. Respectively, oils and high-fat margarines were the main sources of the $n-3$ PUFA intake in the current study population (25). On the other hand, intake of $n-6$ PUFAs in Finland is among the lowest, while intake in the US is among the highest, in the world (23). Accordingly, the mean $n$ 6:n-3 PUFAs ratio was much smaller in the current cohort compared to the US cohort (3.5 vs. 11.1), which may explain the partly contrasting observations (7). The potential unbeneficial effects of high $n$-3 PUFA consumption or a low n-6:n-3 PUFA ratio on adiposity may not have been observed previously due to much lower plant $n-3$ PUFA intakes (7). Cohort studies with the $n-6: n-3$ ratio measured in maternal plasma (9-11) or cord blood (26) show inconsistent associations with offspring adiposity. The only randomized controlled trial designed to assess the effect of a reduced $n-6: n-3$ intake ratio on offspring adiposity showed no difference between the groups (27).

We observed no statistically significant association between $\alpha$-linolenic acid, linoleic acid, arachidonic acid, or trans fatty acids and overweight or obesity, which is in line with the findings from the US cohort (7). Further, the lack of statistically significant associations between total SFAs, monounsaturated fatty acids (MUFAs), and total energy with offspring adiposity is consistent with most previous studies $(8,12,28)$.

In addition to the high variation in fatty acid intakes across studies, the inconsistencies in the existing results may be due to differences in methods, such as stratification by sex, measures and timing of measurement of exposure (fatty acids) and outcome (adiposity), and adjustment for potential confounders. We observed different associations between the maternal $n-6: n-3$ ratio and obesity in girls and boys. This may be a true difference, because there are sex differences in fatty acid metabolism, although little data is available for prepubertal children (29). Fatty acid exposures during different trimesters of pregnancy or during lactation may have different associations with offspring adiposity (7). Most previous cohort studies assessed adiposity at only one age point $(7,9)$, 
while we used repeated measures. In addition, different outcome measures of adiposity, such as BMI, overweight, obesity, or body composition, may result in different associations $(7,10)$. We observed stronger associations when the outcome was obesity compared to overweight, and IOTFdefined obesity compared to WHO-defined obesity, suggesting that the maternal intake of fatty acids might have the most effect on the highest end of the BMI scale.

Despite the inconsistent directions of associations, in our results and in the literature, PUFAs have repeatedly been raised as potential players in adiposity programming. Linoleic acid and $\alpha$-linolenic acid are essential fatty acids and should contribute at least $5 \%$ of the total energy intake in pregnant women (30). The fetus may synthesize SFAs and MUFAs but has a limited capacity to synthesize long-chain-PUFAs, resulting in dependency on maternal PUFA intake and metabolism (5). Therefore, the biological rationale supports our results, in which PUFAs in particular seemed to be important.

The generalizability of our results must be considered, because all children in the present study carried HLA-conferred susceptibility to type 1 diabetes. Rapid growth may be a risk marker for type 1 diabetes (31), and therefore the growth pattern might be different in children who later become diabetic in comparison to those who remain healthy. However, the exclusion of children with advanced preclinical or clinical type 1 diabetes did not change the main results. In addition, the prevalence of overweight and obesity in the present study was very similar to that in a population sample of Finnish children for girls, and only slightly higher for boys (for example, $13 \%$ vs. $11 \%$ in 5-year-olds) (32).

To conclude, maternal intakes of PUFAs in late pregnancy were associated with risk of later obesity differently in girls and boys. We report, for the first time, the lack of associations between maternal antenatal intakes of MUFA 18:1 isomers and individual SFAs with offspring overweight and obesity. 
The authors have no conflicts of interest. RV is a board member at Novo Nordisk Diabetes, Finland, Medtronic Nordic, Lilly Diabetes, Finland, and Sanofi, Finland. She has received payment for an educational presentation from Apothecom, UK.

\section{Acknowledgements}

SV, SLJ, LH, HMT, MK, JI, JT, and RV participated in study design, SA, JR, SLJ, HMT, and SN participated in data processing, HMT analyzed the data, LH generated the figures, LH, H-MT, SN, SMV, and SLJ participated in data interpretation, LH and SLJ wrote the first version of the manuscript, and all authors participated in the revision of the manuscript and have read and accepted the final version. This work was supported by the European Foundation for the Study of Diabetes, the Academy of Finland (grants 63672, 68292, 79685, 79686, 80846, 114666, 126813, 129492, 139391, 201988, 210632, 276475), the Finnish Diabetes Association, the Finnish Diabetes Research Foundation, the Juho Vainio Foundation, Juvenile Diabetes Research Foundation International (grants 4-1998-274, 4-1999-731, 4-2001-435), the Yrjö Jahnsson Foundation, the Competitive State Research Financing of the Expert Responsibility area of Tampere University Hospital (grants 9E082, 9F089, 9G087, 9H092, 9J147, 9K149, 9L042, 9L117, 9M036, 9M114, 9N086, 9P057, 9R055), Oulu University Hospital Research Funds, and a Turku University Hospital Governmental Grant. We thank all the families, study nurses, and research scientists who took part in this study.

\section{References}

1. Barker DJ, Gluckman PD, Godfrey KM, Harding JE, Owens JA, Robinson JS. Fetal nutrition and cardiovascular disease in adult life. Lancet 1993; 341: 938-941.

2. Adamo KB, Ferraro ZM, Brett KE. Can we modify the intrauterine environment to halt the intergenerational cycle of obesity? Int J Environ Res Public Health 2012; 9: 1263-1307.

3. Fernández-Barrés S, Romaguera $\mathrm{D}$, Valvi $\mathrm{D}$, et al. Mediterranean dietary pattern in pregnant women and offspring risk of overweight and abdominal obesity in early childhood: the INMA birth cohort study. Pediatr Obes 2016; Epub ahead of print. 
4. Donnelly JM, Walsh JM, Byrne J, Molloy EJ, McAuliffe FM. Impact of maternal diet on neonatal anthropometry: a randomized controlled trial. Pediatr Obes 2015; 10: 52-56.

5. Mennitti LV, Oliveira JL, Morais CA, et al. Type of fatty acids in maternal diets during pregnancy and/or lactation and metabolic consequences of the offspring. J Nutr Biochem 2015; 26: 99-111.

6. Ailhaud G, Guesnet P. Fatty acid composition of fats is an early determinant of childhood obesity: a short review and an opinion. Obes Rev 2004; 5: 21-26.

7. Donahue SM, Rifas-Shiman SL, Gold DR, Jouni ZE, Gillman MW, Oken E. Prenatal fatty acid status and child adiposity at age 3 y: results from a US pregnancy cohort. Am J Clin Nutr 2011; 93: 780-788.

8. Murrin C, Shrivastava A, Kelleher CC, Lifeways Cross-generation Cohort Study Steering Group. Maternal macronutrient intake during pregnancy and 5 years postpartum and associations with child weight status aged five. Eur J Clin Nutr 2013; 67: 670-679.

9. de Vries PS, Gielen M, Rizopoulos D, et al. Association between polyunsaturated fatty acid concentrations in maternal plasma phospholipids during pregnancy and offspring adiposity at age 7: the MEFAB cohort. Prostaglandins Leukot Essent Fatty Acids 2014; 91: 81-85.

10. Moon RJ, Harvey NC, Robinson SM, et al. Maternal plasma polyunsaturated fatty acid status in late pregnancy is associated with offspring body composition in childhood. J Clin Endocrinol Metab 2013; 98: 299-307.

11. Vidakovic AJ, Gishti O, Voortman T, et al. Maternal plasma PUFA concentrations during pregnancy and childhood adiposity: the Generation R Study. Am J Clin Nutr 2016; 103: 1017-1025.

12. Maslova E, Rytter D, Bech BH, Henriksen TB, Olsen SF, Halldorsson TI. Maternal intake of fat in pregnancy and offspring metabolic health - A prospective study with 20 years of follow-up. Clin Nutr 2016; 35: 475-483.

13. Kupila A, Muona P, Simell T, et al. Feasibility of genetic and immunological prediction of type I diabetes in a population-based birth cohort. Diabetologia 2001; 44: 290-297.

14. Erkkola M, Karppinen M, Javanainen J, Räsänen L, Knip M, Virtanen SM. Validity and reproducibility of a food frequency questionnaire for pregnant Finnish women. Am J Epidemiol 2001; 154: 466-476.

15. Cole TJ, Lobstein T. Extended international (IOTF) body mass index cut-offs for thinness, overweight and obesity. Pediatr Obes 2012; 7: 284-294.

16. WHO Multicentre Growth Reference Study Group. WHO Child Growth Standards: Length/height-for-age, weight-for-age, weight-for-length, weight-for-height and body mass indexfor-age: Methods and development. Geneva: World Health Organization (312 pages). 2006.

17. Abrams B, Carmichael S, Selvin S. Factors associated with the pattern of maternal weight gain during pregnancy. Obstet Gynecol 1995; 86: 170-176. 
18. Willett WC, Howe GR, Kushi LH. Adjustment for total energy intake in epidemiologic studies. Am J Clin Nutr 1997; 65: 1220S-1228S.

19. Prasad M, Lumia M, Erkkola M, et al. Diet composition of pregnant Finnish women: changes over time and across seasons. Public Health Nutr 2010; 13: 939-946.

20. Niinistö S, Takkinen HM, Uusitalo L, et al. Maternal intake of fatty acids and their food sources during lactation and the risk of preclinical and clinical type 1 diabetes in the offspring. Acta Diabetol 2015; 52: 763-772.

21. Rolland-Cachera MF. Childhood obesity: current definitions and recommendations for their use. Int J Pediatr Obes 2011; 6: 325-331.

22. Laitinen TT, Pahkala K, Venn A, et al. Childhood lifestyle and clinical determinants of adult ideal cardiovascular health: the Cardiovascular Risk in Young Finns Study, the Childhood Determinants of Adult Health Study, the Princeton Follow-Up Study. Int J Cardiol 2013; 169: 126132.

23. Micha R, Khatibzadeh S, Shi P, et al. Global, regional, and national consumption levels of dietary fats and oils in 1990 and 2010: a systematic analysis including 266 country-specific nutrition surveys. BMJ 2014; 348: g2272.

24. Pietinen P, Paturi M, Reinivuo H, Tapanainen H, Valsta LM. FINDIET 2007 Survey: energy and nutrient intakes. Public Health Nutr 2010; 13: 920-924.

25. Niinistö S, Takkinen HM, Uusitalo L, et al. Maternal dietary fatty acid intake during pregnancy and the risk of preclinical and clinical type 1 diabetes in the offspring. Br J Nutr 2014; 111: 895903.

26. Standl M, Thiering E, Demmelmair H, Koletzko B, Heinrich J. Age-dependent effects of cord blood long-chain PUFA composition on BMI during the first 10 years of life. Br J Nutr 2014; 111: 2024-2031.

27. Hauner H, Much D, Vollhardt C, et al. Effect of reducing the n-6:n-3 long-chain PUFA ratio during pregnancy and lactation on infant adipose tissue growth within the first year of life: an openlabel randomized controlled trial. Am J Clin Nutr 2012; 95: 383-394.

28. Brion MJ, Ness AR, Rogers I, et al. Maternal macronutrient and energy intakes in pregnancy and offspring intake at $10 \mathrm{y}$ : exploring parental comparisons and prenatal effects. Am J Clin Nutr 2010; 91: 748-756.

29. Decsi T, Kennedy K. Sex-specific differences in essential fatty acid metabolism. Am J Clin Nutr 2011; 94: 1914S-1919S.

30. Nordic Council of Ministers. Nordic Nutrition Recommendations 2012. Integrating nutrition and physical activity. 2012. Nord 2014:002.

31. Hyppönen E, Virtanen SM, Kenward MG, Knip M, Åkerblom HK, Childhood Diabetes in Finland Study Group. Obesity, increased linear growth, and risk of type 1 diabetes in children. Diabetes Care 2000; 23: 1755-1760. 
32. Vuorela N, Saha MT, Salo MK. Change in prevalence of overweight and obesity in Finnish children - comparison between 1974 and 2001. Acta Paediatr 2011; 100: 109-115.

\section{Table and figure legends}

Figure 1. Prevalence of overweight and obesity in boys and girls according to the IOTF and WHO criteria and mean (standard deviation) BMI from 2 to 7 years, the DIPP Nutrition Study, Finland.

IOTF $=$ International Obesity Task Force, $\mathrm{WHO}=$ World Health Organization, $\mathrm{BMI}=$ Body mass index, $\mathrm{SD}=$ Standard deviation. The number of participants at the ages of 2, 3, 4, 5, 6, and 7 years were 1873, 1722, 1562,1470, 1371 and 1240 for boys and 1678, 1567, 1451, 1330, 1230, and 1154 for girls, respectively. Children aged 2 years \pm 3 months were included, but the IOTF criteria start at 2.0 years. Therefore, the number of participants with the IOTF-defined variables at the age of 2 years were 1408 for boys and 1243 for girls. The light grey represents overweight without obesity, and the total bar represents overweight including obesity.

Table 1. Characteristics of 3807 mothers and their offspring by sex in relation to childhood overweight (including obesity), and obesity from the ages of 2 to 7 years according to the IOTF criteria, the DIPP Nutrition Study, Finland.

$\mathrm{BMI}=$ body mass index; IQR $=$ interquartile range ${ }^{\mathrm{a}} \mathrm{p}$-value for difference between girls and boys from the Mann-Whitney $U$ test;

${ }^{b} \mathrm{OR}(95 \% \mathrm{CI})$ for overweight (including obesity) and obesity, based on unadjusted generalized estimating equation models;

${ }^{\mathrm{c}}$ At the time of birth;

${ }^{\mathrm{d}}$ Based on the first weight measurement during pregnancy: If the first weight measurement was after the tenth week of gestation, the weight at the tenth week was estimated based on the weight

difference between the first and last antenatal visit, assuming a linear weight gain during the second and third trimesters of pregnancy;

${ }^{\mathrm{e}}$ Adjusted with maternal early pregnancy BMI and the time of the first weight measurement $(\leq 10.0$ vs. >10 weeks of pregnancy);

${ }_{\mathrm{p}}^{\mathrm{p}}$-value for the difference between girls and boys from the Chi-Square test;

${ }^{\mathrm{g}} \mathrm{p}$-value from type 3 Score test

The number of individuals with missing data for covariates varied in general between 0 and 100 . However, data for early pregnancy BMI was missing in 204 mothers and for gestational weight gain rate in 226 mothers.

Table 2. Adjusted odds ratios (OR) for offspring overweight (including obesity) and obesity based on IOTF criteria from the ages of 2 to 7 years according to quartiles of maternal energy and fatty acid intake during pregnancy in 3807 mother-child pairs, the DIPP Nutrition Study, Finland.

The OR (95\% CI) are from generalized estimating equations adjusted for maternal early pregnancy BMI, gestational weight gain rate, time of the first weight measurement $(\leq 10.0 \mathrm{vs}$. $>10$ weeks of 
pregnancy), glucose intolerance diet, education, smoking during pregnancy, and duration of breastfeeding. p-values are based on type 3 Score test. The fatty acid variables used in the statistical analysis were energy-adjusted using Willett's residual method after logarithmic transformation. The sum of the 18:1 isomers consists mainly of oleic acid (18:1 n-9) and cis-vaccenic acid (18:1 n-7). $\mathrm{IOTF}=$ International Obesity Task Force; $\mathrm{E} \%=$ percent of daily energy intake; SFA = Saturated fatty acid; MUFA = Monounsaturated fatty acid; PUFA = Polyunsaturated fatty acid; DHA = Docosahexaenoic acid; EPA = Eicosapentaenoic acid; $\mathrm{Q}_{1}=1^{\text {st }}$ quartile; $\mathrm{Q}_{2-3}=$ the 2 middle quartiles; $\mathrm{Q}_{4}=4^{\text {th }}$ quartile 
Table 1. Characteristics of 3807 mothers and their offspring by sex in relation to childhood overweight (including obesity), and obesity from the ages of 2 to 7 years according to the IOTF criteria, the DIPP Nutrition Study, Finland.

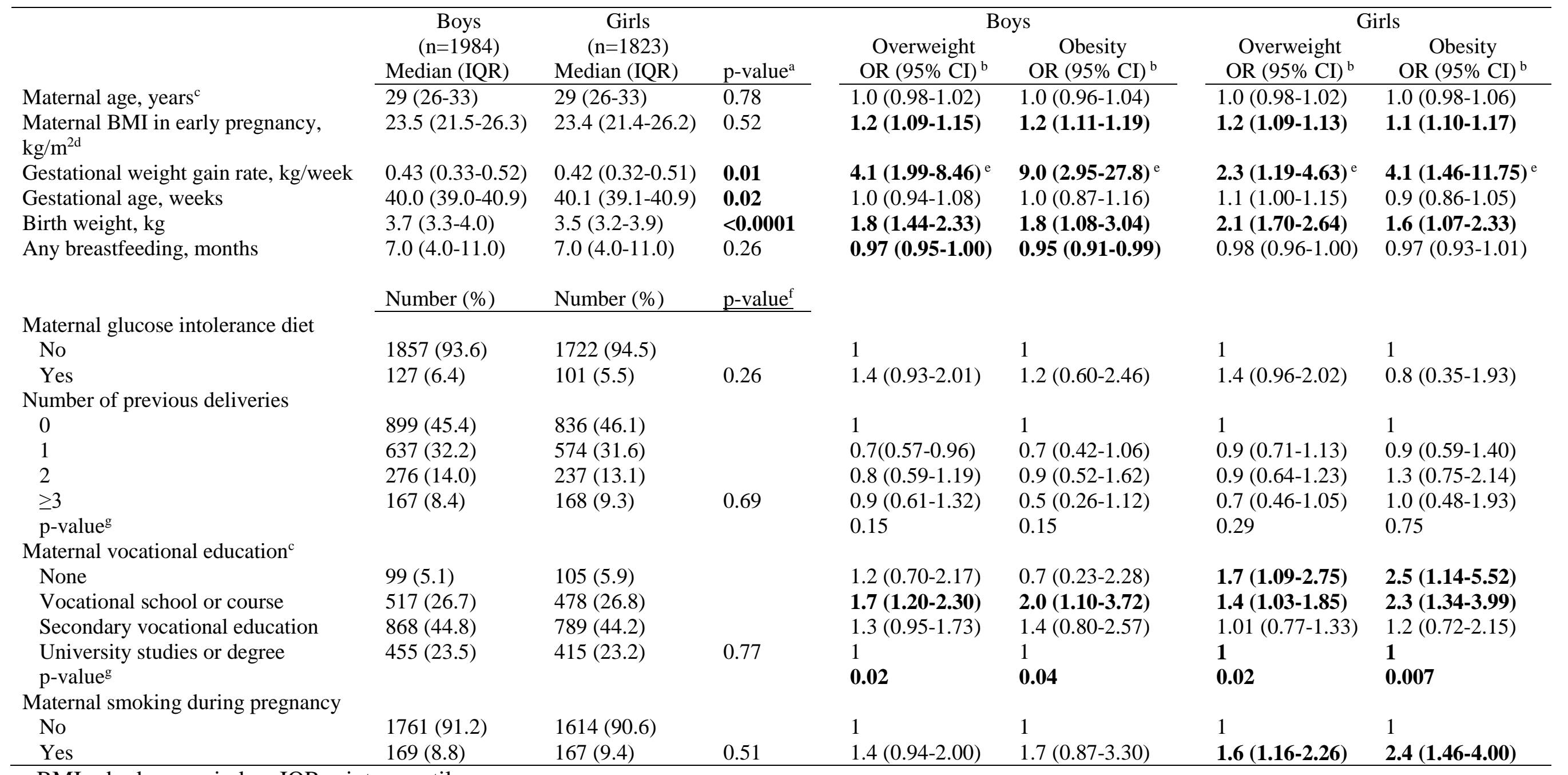

$\mathrm{BMI}=$ body mass index; IQR $=$ interquartile range

${ }^{\mathrm{a}} \mathrm{p}$-value for difference between girls and boys from the Mann-Whitney $U$ test;

${ }^{\mathrm{b}} \mathrm{OR}(95 \% \mathrm{CI})$ for overweight (including obesity) and obesity, based on unadjusted generalized estimating equation models;

${ }^{\mathrm{c}}$ At the time of birth; 
${ }^{\mathrm{d}}$ Based on the first weight measurement during pregnancy: If the first weight measurement was after the tenth week of gestation, the weight at the tenth week was estimated based on the weight difference between the first and last antenatal visit, assuming a linear weight gain during the second and third trimesters of pregnancy;

${ }^{\mathrm{e}}$ Adjusted with maternal early pregnancy BMI and the time of the first weight measurement ( $\leq 10.0 \mathrm{vs}>10$ weeks of pregnancy);

${ }_{\mathrm{p}}^{\mathrm{f}}$-value for the difference between girls and boys from the Chi-Square test;

${ }_{\mathrm{g}}^{\mathrm{p}}$-value from type 3 Score test

The number of individuals with missing data for covariates varied in general between 0 and 100 . However, data for early pregnancy BMI was missing in 204 mothers and for gestational weight gain rate in 226 mothers. 
Table 2. Adjusted odds ratios (OR) for offspring overweight (including obesity) and obesity based on IOTF criteria from the ages of 2 to 7 years according to quartiles of maternal energy and fatty acid intake during pregnancy in 3807 mother-child pairs, the DIPP Nutrition Study, Finland.

\begin{tabular}{|c|c|c|c|c|}
\hline & \multicolumn{2}{|c|}{ Boys $(n=1984)$} & \multicolumn{2}{|c|}{ Girls $(n=1823)$} \\
\hline & Overweight & Obesity & Overweight & Obesity \\
\hline & OR $(95 \% \mathrm{CI})$ & OR $(95 \% \mathrm{CI})$ & OR $(95 \% \mathrm{CI})$ & OR $(95 \% \mathrm{CI})$ \\
\hline \multicolumn{5}{|l|}{ Total energy intake, $\mathrm{kJ}$} \\
\hline $\mathrm{Q}_{1}<9300$ & $1.1(0.79-1.45)$ & $1.2(0.69-1.97)$ & $1.1(0.82-1.43)$ & $1.3(0.82-2.11)$ \\
\hline $\mathrm{Q}_{2-3} 9300-13400$ & 1 & 1 & 1 & 1 \\
\hline $\mathrm{Q}_{4}>13400$ & $1.3(0.97-1.71)$ & $1.5(0.93-2.57)$ & $0.9(0.73-1.23)$ & $0.8(0.50-1.35)$ \\
\hline $\mathrm{p}$-value & 0.25 & 0.32 & 0.70 & 0.27 \\
\hline \multicolumn{5}{|l|}{ Carbohydrates, E\% } \\
\hline $\mathrm{Q}_{1}<47.2$ & $0.8(0.62-1.14)$ & $0.9(0.54-1.64)$ & $1.1(0.80-1.41)$ & $1.0(0.63-1.62)$ \\
\hline $\mathrm{Q}_{2-3} 47.2-53.8$ & 1 & 1 & 1 & 1 \\
\hline $\mathrm{Q}_{4}>53.8$ & $1.0(0.75-1.32)$ & $1.0(0.61-1.65)$ & $1.3(1.01-1.72)$ & $1.1(0.70-1.86)$ \\
\hline p-value & 0.49 & 0.97 & 0.15 & 0.87 \\
\hline \multicolumn{5}{|l|}{ Proteins, E\% } \\
\hline $\mathrm{Q}_{1}<14.7$ & $0.9(0.64-1.17)$ & $0.8(0.46-1.35)$ & $1.4(1.03-1.78)$ & $1.2(0.72-2.00)$ \\
\hline $\mathrm{Q}_{2-3} 14.7-17.5$ & 1 & 1 & 1 & 1 \\
\hline $\mathrm{Q}_{4}>17.5$ & $1.0(0.72-1.29)$ & $1.1(0.64-1.79)$ & $1.2(0.92-1.59)$ & $1.3(0.83-2.06)$ \\
\hline p-value & 0.62 & 0.56 & 0.08 & 0.49 \\
\hline \multicolumn{5}{|l|}{ Fats, E\% } \\
\hline $\mathrm{Q}_{1}<30.0$ & $1.0(0.75-1.30)$ & $0.9(0.56-1.51)$ & $1.1(0.85-1.45)$ & $0.8(0.48-1.27)$ \\
\hline $\mathrm{Q}_{2-3} 30.0-36.4$ & 1 & 1 & 1 & 1 \\
\hline $\mathrm{Q}_{4}>36.4$ & $0.8(0.58-1.06)$ & $1.0(0.57-1.63)$ & $1.0(0.75-1.33)$ & $0.9(0.53-1.40)$ \\
\hline p-value & 0.23 & 0.94 & 0.74 & 0.56 \\
\hline \multicolumn{5}{|l|}{ SFA, g } \\
\hline $\mathrm{Q}_{1}$ & $1.0(0.77-1.37)$ & $1.1(0.64-1.74)$ & $1.2(0.92-1.56)$ & $0.8(0.51-1.38)$ \\
\hline $\mathrm{Q}_{2-3}$ & 1 & 1 & 1 & 1 \\
\hline $\mathrm{Q}_{4}$ & $1.0(0.72-1.30)$ & $1.1(0.64-1.79)$ & $1.1(0.81-1.45)$ & $0.9(0.55-1.48)$ \\
\hline $\mathrm{p}$-value & 0.94 & 0.96 & 0.43 & 0.75 \\
\hline \multicolumn{5}{|l|}{ Myristic acid (14:0), g } \\
\hline $\mathrm{Q}_{1}$ & $0.9(0.69-1.23)$ & $0.8(0.49-1.36)$ & $1.2(0.92-1.55)$ & $1.1(0.67-1.74)$ \\
\hline $\mathrm{Q}_{2-3}$ & 1 & 1 & 1 & 1 \\
\hline $\mathrm{Q}_{4}$ & $1.0(0.76-1.37)$ & $1.0(0.61-1.75)$ & $1.0(0.74-1.31)$ & $1.2(0.71-1.95)$ \\
\hline $\mathrm{p}$-value & 0.82 & 0.65 & 0.39 & 0.81 \\
\hline \multicolumn{5}{|l|}{ Palmitic acid (16:0), g } \\
\hline $\mathrm{Q}_{1}$ & $1.0(0.75-1.31)$ & $1.1(0.67-1.79)$ & $1.2(0.90-1.53)$ & $0.7(0.43-1.18)$ \\
\hline $\mathrm{Q}_{2-3}$ & 1 & 1 & 1 & 1 \\
\hline $\mathrm{Q}_{4}$ & $0.9(0.64-1.18)$ & $1.2(0.73-2.11)$ & $1.1(0.84-1.48)$ & $0.8(0.50-1.32)$ \\
\hline $\mathrm{p}$-value & 0.63 & 0.75 & 0.49 & 0.36 \\
\hline \multicolumn{5}{|l|}{ Stearic acid (18:0), mg } \\
\hline $\mathrm{Q}_{1}$ & $1.2(0.93-1.62)$ & $1.3(0.78-2.03)$ & $1.3(1.00-1.71)$ & $0.9(0.57-1.45)$ \\
\hline $\mathrm{Q}_{2-3}$ & 1 & 1 & 1 & 1 \\
\hline $\mathrm{Q}_{4}$ & $0.8(0.62-1.15)$ & $0.9(0.53-1.59)$ & $1.1(0.84-1.48)$ & $0.8(0.48-1.29)$ \\
\hline $\mathrm{p}$-value & 0.11 & 0.53 & 0.16 & 0.63 \\
\hline \multicolumn{5}{|l|}{ MUFA, $\mathrm{g}$} \\
\hline $\mathrm{Q}_{1}$ & $1.0(0.80-1.39)$ & $1.1(0.70-1.84)$ & $1.0(0.78-1.34)$ & $0.8(0.50-1.33)$ \\
\hline $\mathrm{Q}_{2-3}$ & 1 & 1 & 1 & 1 \\
\hline $\mathrm{Q}_{4}$ & $0.8(0.61-1.11)$ & $0.9(0.54-1.61)$ & $1.0(0.75-1.33)$ & $0.8(0.50-1.37)$ \\
\hline $\mathrm{p}$-value & 0.28 & 0.80 & 0.99 & 0.61 \\
\hline \multicolumn{5}{|l|}{ Sum of $18: 1$ isomers, $g$} \\
\hline $\mathrm{Q}_{1}$ & $1.0(0.79-1.39)$ & $1.2(0.71-1.87)$ & $1.0(0.78-1.34)$ & $0.8(0.47-1.28)$ \\
\hline $\mathrm{Q}_{2-3}$ & 1 & 1 & 1 & 1 \\
\hline
\end{tabular}




\begin{tabular}{|c|c|c|c|c|}
\hline $\begin{array}{l}\mathrm{Q}_{4} \\
\mathrm{p} \text {-value }\end{array}$ & $\begin{array}{l}0.8(0.61-1.10) \\
0.28\end{array}$ & $\begin{array}{l}0.9(0.55-1.63) \\
0.79\end{array}$ & $\begin{array}{l}1.0(0.75-1.33) \\
0.99\end{array}$ & $\begin{array}{l}0.8(0.50-1.36) \\
0.57\end{array}$ \\
\hline \multicolumn{5}{|l|}{ PUFA, g } \\
\hline $\mathrm{Q}_{1}$ & $1.2(0.89-1.57)$ & $1.6(0.98-2.75)$ & $1.1(0.84-1.44)$ & $1.2(0.73-1.87)$ \\
\hline $\mathrm{Q}_{2-3}$ & 1 & 1 & 1 & \\
\hline $\mathrm{Q}_{4}$ & $0.9(0.66-1.23)$ & $1.2(0.70-2.11)$ & $0.9(0.70-1.22)$ & $1.0(0.61-1.69)$ \\
\hline p-value & 0.30 & 0.22 & 0.55 & 0.81 \\
\hline \multicolumn{5}{|l|}{ n-3 PUFA, g } \\
\hline $\mathrm{Q}_{1}$ & $1.0(0.76-1.36)$ & $1.3(0.75-2.12)$ & $1.3(0.96-1.64)$ & $1.9(1.17-2.93)$ \\
\hline $\mathrm{Q}_{2-3}$ & 1 & 1 & 1 & 1 \\
\hline $\mathrm{Q}_{4}$ & $0.9(0.69-1.24)$ & $1.1(0.63-1.81)$ & $1.1(0.79-1.39)$ & $1.7(1.02-2.73)$ \\
\hline $\mathrm{p}$-value & 0.83 & 0.71 & 0.26 & 0.02 \\
\hline \multicolumn{5}{|c|}{$\alpha$-Linolenic acid (18:3n-3), g } \\
\hline $\mathrm{Q}_{1}$ & $1.0(0.74-1.32)$ & $1.4(0.79-2.30)$ & $1.1(0.84-1.45)$ & $1.5(0.91-2.33)$ \\
\hline $\mathrm{Q}_{2-3}$ & 1 & 1 & 1 & 1 \\
\hline $\mathrm{Q}_{4}$ & $1.0(0.78-1.41)$ & $1.1(0.68-1.92)$ & $1.0(0.77-1.35)$ & $1.2(0.73-1.99)$ \\
\hline $\mathrm{p}$-value & 0.94 & 0.57 & 0.77 & 0.30 \\
\hline \multicolumn{5}{|c|}{ EPA $(20: 5 n-3), \mathrm{mg}$} \\
\hline $\mathrm{Q}_{1}$ & $0.8(0.62-1.13)$ & $0.5(0.27-0.94)$ & $1.1(0.80-1.39)$ & $0.9(0.58-1.47)$ \\
\hline $\mathrm{Q}_{2-3}$ & 1 & 1 & 1 & 1 \\
\hline $\mathrm{Q}_{4}$ & $1.0(0.75-1.35)$ & $1.0(0.61-1.70)$ & $0.9(0.68-1.19)$ & $0.8(0.48-1.31)$ \\
\hline p-value & 0.45 & 0.03 & 0.61 & 0.65 \\
\hline \multicolumn{5}{|c|}{ DHA (22:6n-3), mg } \\
\hline $\mathrm{Q}_{1}$ & $0.9(0.65-1.20)$ & $0.6(0.31-1.06)$ & $1.1(0.81-1.40)$ & $0.9(0.56-1.44)$ \\
\hline $\mathrm{Q}_{2-3}$ & 1 & 1 & 1 & 1 \\
\hline $\mathrm{Q}_{4}$ & $1.1(0.82-1.47)$ & $1.0(0.61-1.70)$ & $0.9(0.69-1.20)$ & $0.8(0.48-1.30)$ \\
\hline $\mathrm{p}$-value & 0.48 & 0.12 & 0.63 & 0.63 \\
\hline \multicolumn{5}{|l|}{ n-6 PUFA, g } \\
\hline $\mathrm{Q}_{1}$ & $1.1(0.85-1.50)$ & $1.5(0.88-2.42)$ & $0.9(0.71-1.22)$ & $1.0(0.62-1.60)$ \\
\hline $\mathrm{Q}_{2-3}$ & 1 & 1 & 1 & 1 \\
\hline $\mathrm{Q}_{4}$ & $0.8(0.56-1.02)$ & $1.0(0.56-1.68)$ & $0.8(0.64-1.12)$ & $0.8(0.48-1.35)$ \\
\hline p-value & 0.048 & 0.36 & 0.47 & 0.68 \\
\hline \multicolumn{5}{|c|}{ Linoleic acid (18:2n-6), g } \\
\hline $\mathrm{Q}_{1}$ & $1.2(0.89-1.57)$ & $1.6(0.95-2.67)$ & $1.0(0.73-1.25)$ & $1.1(0.66-1.71)$ \\
\hline $\mathrm{Q}_{2-3}$ & 1 & 1 & 1 & 1 \\
\hline $\mathrm{Q}_{4}$ & $0.8(0.61-1.11)$ & $1.0(0.60-1.80)$ & $0.9(0.66-1.16)$ & $0.9(0.55-1.52)$ \\
\hline p-value & 0.11 & 0.26 & 0.63 & 0.87 \\
\hline \multicolumn{5}{|c|}{$\begin{array}{l}\text { Arachidonic acid }(20: 4 n-6) \text {, } \\
\text { mg }\end{array}$} \\
\hline $\mathrm{Q}_{1}$ & $0.8(0.61-1.13)$ & $0.7(0.40-1.26)$ & $1.0(0.77-1.34)$ & $1.0(0.59-1.59)$ \\
\hline $\mathrm{Q}_{2-3}$ & 1 & 1 & 1 & 1 \\
\hline $\mathrm{Q}_{4}$ & $0.7(0.55-0.98)$ & $0.8(0.46-1.32)$ & $0.9(0.68-1.19)$ & $1.0(0.63-1.61)$ \\
\hline p-value & 0.09 & 0.39 & 0.71 & 0.99 \\
\hline \multicolumn{5}{|c|}{$\gamma$-Linoleic acid (18:3n-6), mg } \\
\hline $\mathrm{Q}_{1}$ & $0.9(0.70-1.22)$ & $1.2(0.73-1.82)$ & $1.1(0.85-1.46)$ & $0.9(0.55-1.43)$ \\
\hline $\mathrm{Q}_{2-3}$ & 1 & 1 & 1 & 1 \\
\hline $\mathrm{Q}_{4}$ & $0.9(0.68-1.24)$ & $0.8(0.46-1.52)$ & $1.0(0.74-1.31)$ & $1.2(0.72-1.96)$ \\
\hline p-value & 0.79 & 0.56 & 0.68 & 0.64 \\
\hline \multicolumn{5}{|c|}{$\begin{array}{l}\text { Conjugated linoleic acid } \\
(18: 2 n-6), \mathrm{mg}\end{array}$} \\
\hline $\mathrm{Q}_{1}$ & $0.8(0.59-1.07)$ & $0.8(0.50-1.32)$ & $1.0(0.79-1.35)$ & $0.8(0.51-1.33)$ \\
\hline $\mathrm{Q}_{2-3}$ & 1 & 1 & 1 & 1 \\
\hline $\mathrm{Q}_{4}$ & $1.0(0.71-1.30)$ & $0.9(0.48-1.60)$ & $1.0(0.72-1.28)$ & $1.0(0.61-1.66)$ \\
\hline p-value & 0.28 & 0.68 & 0.91 & 0.71 \\
\hline
\end{tabular}

Trans fatty acids, $g$ 


\begin{tabular}{|c|c|c|c|c|}
\hline $\mathrm{Q}_{1}$ & $1.1(0.83-1.48)$ & $1.1(0.70-1.87)$ & $1.1(0.85-1.47)$ & $1.0(0.61-1.63)$ \\
\hline $\mathrm{Q}_{2-3}$ & 1 & 1 & 1 & 1 \\
\hline $\mathrm{Q}_{4}$ & $1.4(1.02-1.82)$ & $1.5(0.85-2.51)$ & $1.0(0.80-1.39)$ & $1.2(0.73-1.95)$ \\
\hline $\mathrm{p}$-value & 0.13 & 0.44 & 0.72 & 0.78 \\
\hline \multicolumn{5}{|l|}{ Ratios } \\
\hline \multicolumn{5}{|l|}{$n-6: n-3$} \\
\hline $\mathrm{Q}_{1}$ & $1.0(0.74-1.31)$ & $0.8(0.51-1.40)$ & $1.4(1.07-1.81)$ & $2.0(1.27-3.20)$ \\
\hline $\mathrm{Q}_{2-3}$ & 1 & 1 & 1 & 1 \\
\hline $\mathrm{Q}_{4}$ & $0.9(0.69-1.26)$ & $1.0(0.61-1.78)$ & $1.1(0.83-1.45)$ & $1.7(1.03-2.73)$ \\
\hline p-value & 0.91 & 0.75 & 0.07 & 0.01 \\
\hline \multicolumn{5}{|c|}{$\begin{array}{l}\text { Linoleic acid }(18: 2 n-6): \alpha- \\
\text { Linolenic acid }(18: 3 n-3)\end{array}$} \\
\hline $\mathrm{Q}_{1}$ & $1.1(0.82-1.46)$ & $1.0(0.57-1.61)$ & $1.4(1.05-1.81)$ & $1.8(1.12-2.93)$ \\
\hline $\mathrm{Q}_{2-3}$ & 1 & 1 & 1 & 1 \\
\hline $\mathrm{Q}_{4}$ & $0.9(0.66-1.19)$ & $1.0(0.58-1.66)$ & $1.2(0.91-1.58)$ & $1.7(1.07-2.84)$ \\
\hline p-value & 0.46 & 0.99 & 0.07 & 0.02 \\
\hline \multicolumn{5}{|c|}{$\begin{array}{l}\text { Arachidonic acid (20:4n- } \\
6 \text { ):DHA+EPA }\end{array}$} \\
\hline $\mathrm{Q}_{1}$ & $1.1(0.78-1.41)$ & $1.0(0.60-1.57)$ & $1.0(0.78-1.36)$ & $1.0(0.62-1.64)$ \\
\hline $\mathrm{Q}_{2-3}$ & 1 & 1 & 1 & 1 \\
\hline $\mathrm{Q}_{4}$ & $0.8(0.58-1.07)$ & $0.5(0.26-0.88)$ & $0.9(0.71-1.23)$ & $0.8(0.46-1.26)$ \\
\hline p-value & 0.20 & 0.02 & 0.83 & 0.49 \\
\hline
\end{tabular}

The OR $(95 \% \mathrm{CI})$ are from generalized estimating equations adjusted for maternal early pregnancy BMI, gestational weight gain rate, time of the first weight measurement $(\leq 10.0$ vs $>10$ weeks of pregnancy) glucose intolerance diet, education, smoking during pregnancy, and duration of breastfeeding. p-values are based on type 3 Score test. The fatty acid variables used in statistical analysis were energy-adjusted using Willett's residual method after logarithmic transformation. The sum of the 18:1 isomers consists mainly of oleic acid (18:1 n-9) and cis-vaccenic acid (18:1 n-7). IOTF = International Obesity Task Force; E\% = percent of daily energy intake; SFA = Saturated fatty acid; MUFA = Monounsaturated fatty acid; PUFA = Polyunsaturated fatty acid; DHA = Docosahexaenoic acid; EPA = Eicosapentaenoic acid; $\mathrm{Q}_{1}=1^{\text {st }}$ quartile; $\mathrm{Q}_{2-3}=$ the 2 middle quartiles; $\mathrm{Q}_{4}=4^{\text {th }}$ quartile. 
Figure S1. Flowchart of the DIPP Nutrition Study recruitment and formation of the present study population.

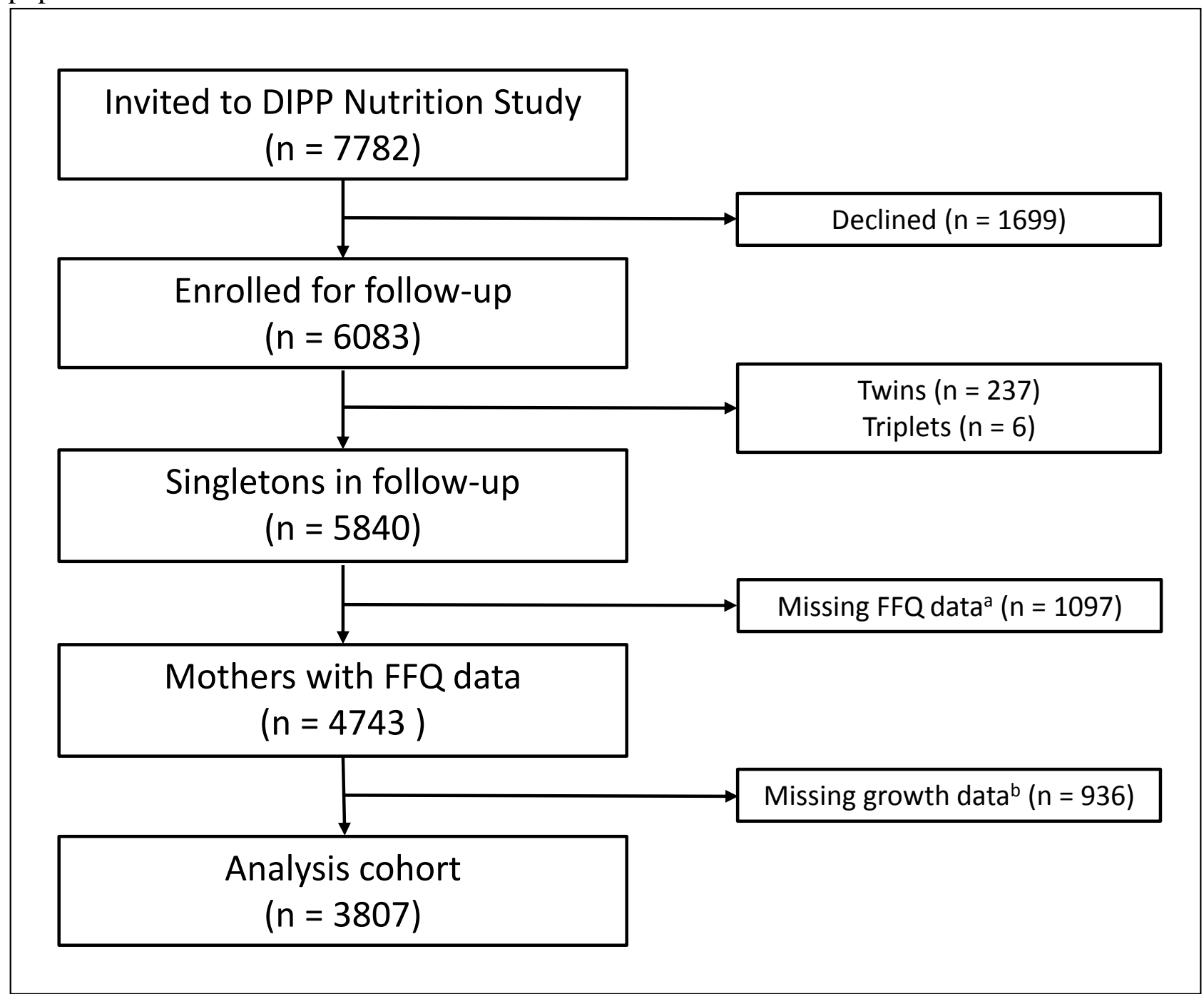

${ }^{a}$ No FFQ (food frequency questionnaire) or FFQ with $>10$ missing items.

${ }^{b}$ No data on birth size or at least one weight and height measure between 2 and 7 years $( \pm 3$ months) 
Table S1. Food frequency questionnaire-based dietary intake of carbohydrates, proteins and fats, with emphasis on fatty acids in 3807 mothers during eighth month of pregnancy, the DIPP Nutrition Study, Finland.

\begin{tabular}{|c|c|c|}
\hline & $\begin{array}{l}\text { Absolute intake } \\
\text { Mean (SD) }\end{array}$ & $\begin{array}{l}\text { Percent of total } \\
\text { energy intake, E\% } \\
\text { Mean (SD) }\end{array}$ \\
\hline Total energy intake, $\mathrm{kJ} /$ day & $11623(3364)$ & \\
\hline Carbohydrates, g & $327(101)$ & $50.6(5.1)$ \\
\hline Proteins, $\mathrm{g}$ & $109(32)$ & $16.1(2.2)$ \\
\hline Fats (total), $\mathrm{g}$ & $105(36)$ & $33.2(4.8)$ \\
\hline Fats, triacylglycerols, $\mathrm{g}$ & $98(34)$ & \\
\hline SFA, $g$ & $43.3(16.7)$ & $13.7(2.7)$ \\
\hline Myristic acid(14:0), g & $4.8(2.0)$ & \\
\hline Pentadecanoid acid (15:0), mg & $618(284)$ & \\
\hline Palmitic acid (16:0), $\mathrm{g}$ & $20.3(7.5)$ & \\
\hline Stearic acid (18:0), mg & $10.6(4.3)$ & \\
\hline MUFA, $\mathrm{g}$ & $35.6(12.4)$ & $11.3(1.9)$ \\
\hline Sum of $18: 1$ isomers, $g$ & $32.7(11.5)$ & \\
\hline PUFA, g & $13.7(5.0)$ & $4.4(1.0)$ \\
\hline$n-3$ PUFA, g & $3.1(1.2)$ & $1.0(0.3)$ \\
\hline$\alpha$-Linolenic acid (18:3n-3), g & $2.5(1.0)$ & \\
\hline EPA $(20: 5 n-3), \mathrm{mg}$ & $98.4(84.8)$ & \\
\hline DHA (22:6n-3), mg & $261(220)$ & \\
\hline$n-6$ PUFA, g & $10.3(3.8)$ & $3.3(0.8)$ \\
\hline Linoleic acid $(18: 2 n-6), \mathrm{g}$ & $10.0(3.7)$ & \\
\hline Arachidonic acid (20:4n-6), mg & $97.3(41.2)$ & \\
\hline$\gamma$-Linoleic acid $(18: 3 n-6), \mathrm{mg}$ & $57.5(32.2)$ & \\
\hline Conjugated linoleic acid $(18: 2 n-6), \mathrm{mg}$ & $181(80.8)$ & \\
\hline Trans fatty acids, $\mathrm{g}$ & $1.3(0.6)$ & \\
\hline \multicolumn{3}{|l|}{ Ratios } \\
\hline$n-6: n-3$ & $3.5(0.8)$ & \\
\hline $\begin{array}{l}\text { Linoleic acid }(18: 2 n-6): \alpha \text {-Linolenic acid } \\
(18: 3 n-3)\end{array}$ & $4.2(1.0)$ & \\
\hline Arachidonic acid (20:4n-6):DHA+EPA & $0.43(0.36)$ & \\
\hline
\end{tabular}

SFA = Saturated fatty acid; MUFA = Monounsaturated fatty acid; PUFA = Polyunsaturated fatty acid; DHA $=$ Docosahexaenoic acid; EPA $=$ Eicosapentaenoic acid; Total energy and carbohydrates include the calculated energy from fibre. Sum of 18:1 isomers consists mainly of oleic acid (18:1n-9) and cis-vaccenic acid (18:1 n-7). 
Table S2. Unadjusted odds ratios (OR) for offspring overweight (including obesity) and obesity based on IOTF criteria from ages of 2 to 7 years according to quartiles of maternal energy and fatty acid intake during pregnancy in 3807 mother-child pairs, the DIPP Nutrition Study, Finland.

\begin{tabular}{|c|c|c|c|c|}
\hline & \multicolumn{2}{|c|}{ Boys $(n=1984)$} & \multicolumn{2}{|c|}{ Girls $(n=1823)$} \\
\hline & Overweight & Obesity & Overweight & Obesity \\
\hline & OR $(95 \% \mathrm{CI})$ & OR $(95 \% \mathrm{CI})$ & OR $(95 \% \mathrm{CI})$ & OR $(95 \% \mathrm{CI})$ \\
\hline \multicolumn{5}{|l|}{ Total energy intake, $\mathrm{kJ}$} \\
\hline $\mathrm{Q}_{1}<9300$ & $1.0(0.78-1.35)$ & $1.1(0.65-1.72)$ & $1.2(0.92-1.53)$ & $1.4(0.87-2.10)$ \\
\hline $\mathrm{Q}_{2-3} 9300-13400$ & 1 & 1 & 1 & 1 \\
\hline $\mathrm{Q}_{4}>13400$ & $1.3(0.99-1.69)$ & $1.4(0.85-2.20)$ & $1.07(0.84-1.37)$ & $1.0(0.63-1.55)$ \\
\hline $\mathrm{p}$-value & 0.19 & 0.48 & 0.43 & 0.40 \\
\hline \multicolumn{5}{|l|}{ Carbohydrates, E\% } \\
\hline $\mathrm{Q}_{1}<47.2$ & $0.8(0.61-1.08)$ & $0.9(0.56-1.54)$ & $1.0(0.80-1.34)$ & $1.0(0.63-1.54)$ \\
\hline $\mathrm{Q}_{2-3} 47.2-53.8$ & 1 & 1 & 1 & 1 \\
\hline $\mathrm{Q}_{4}>53.8$ & $0.9(0.72-1.23)$ & $1.0(0.62-1.56)$ & $1.2(0.96-1.58)$ & $1.2(0.77-1.86)$ \\
\hline p-value & 0.33 & 0.96 & 0.26 & 0.74 \\
\hline \multicolumn{5}{|l|}{ Proteins, E\% } \\
\hline $\mathrm{Q}_{1}<14.7$ & $0.9(0.67-1.16)$ & $0.9(0.54-1.47)$ & $1.4(1.06-1.75)$ & $1.4(0.90-2.20)$ \\
\hline $\mathrm{Q}_{2-3} 14.7-17.5$ & 1 & 1 & 1 & 1 \\
\hline $\mathrm{Q}_{4}>17.5$ & $1.0(0.80-1.36)$ & $1.2(0.78-1.97)$ & $1.2(0.97-1.60)$ & $1.3(0.81-1.93)$ \\
\hline p-value & 0.52 & 0.52 & 0.04 & 0.30 \\
\hline \multicolumn{5}{|l|}{ Fats, E\% } \\
\hline $\mathrm{Q}_{1}<30.0$ & $1.0(0.74-1.26)$ & $0.9(0.55-1.43)$ & $1.1(0.87-1.43)$ & $0.9(0.57-1.41)$ \\
\hline $\mathrm{Q}_{2-3} 30.0-36.4$ & 1 & 1 & & 1 \\
\hline $\mathrm{Q}_{4}>36.4$ & $0.8(0.60-1.06)$ & $1.0(0.63-1.63)$ & $1.0(0.79-1.32)$ & $0.9(0.59-1.45)$ \\
\hline p-value & 0.26 & 0.85 & 0.68 & 0.88 \\
\hline \multicolumn{5}{|l|}{ SFA, $g$} \\
\hline $\mathrm{Q}_{1}$ & $1.0(0.75-1.27)$ & $0.9(0.57-1.47)$ & $1.1(0.85-1.38)$ & $0.7(0.44-1.15)$ \\
\hline $\mathrm{Q}_{2-3}$ & 1 & 1 & 1 & 1 \\
\hline $\mathrm{Q}_{4}>$ & $0.9(0.69-1.20)$ & $1.1(0.66-1.73)$ & $1.0(0.76-1.27)$ & $0.8(0.51-1.27)$ \\
\hline $\mathrm{p}$-value & 0.78 & 0.85 & 0.77 & 0.31 \\
\hline \multicolumn{5}{|l|}{ Myristic acid (14:0), g } \\
\hline $\mathrm{Q}_{1}$ & $1.0(0.76-1.30)$ & $0.9(0.56-1.46)$ & $1.3(0.98-1.59)$ & $1.2(0.77-1.85)$ \\
\hline $\mathrm{Q}_{2-3}$ & 1 & 1 & 1 & 1 \\
\hline $\mathrm{Q}_{4}$ & $1.0(0.73-1.27)$ & $1.0(0.60-1.60)$ & $1.0(0.74-1.25)$ & $1.1(0.69-1.70)$ \\
\hline $\mathrm{p}$-value & 0.96 & 0.91 & 0.13 & 0.76 \\
\hline \multicolumn{5}{|l|}{ Palmitic acid (16:0), g } \\
\hline $\mathrm{Q}_{1}$ & $0.9(0.72-1.23)$ & $1.0(0.61-1.58)$ & $1.1(0.86-1.40)$ & $0.7(0.42-1.09)$ \\
\hline $\mathrm{Q}_{2-3}$ & 1 & 1 & 1 & 1 \\
\hline $\mathrm{Q}_{4}$ & $0.9(0.66-1.16)$ & $1.3(0.81-2.09)$ & $1.1(0.82-1.38)$ & $0.8(0.51-1.25)$ \\
\hline $\mathrm{p}$-value & 0.65 & 0.55 & 0.75 & 0.22 \\
\hline \multicolumn{5}{|l|}{ Stearic acid (18:0), mg } \\
\hline $\mathrm{Q}_{1}$ & $1.1(0.87-1.47)$ & $1.0(0.65-1.62)$ & $1.2(0.97-1.58)$ & $0.9(0.54-1.34)$ \\
\hline $\mathrm{Q}_{2-3}$ & 1 & 1 & 1 & 1 \\
\hline $\mathrm{Q}_{4}$ & $0.9(0.70-1.24)$ & $1.1(0.70-1.89)$ & $1.2(0.93-1.54)$ & $1.0(0.64-1.56)$ \\
\hline $\mathrm{p}$-value & 0.46 & 0.87 & 0.18 & 0.76 \\
\hline \multicolumn{5}{|l|}{ MUFA, $\mathrm{g}$} \\
\hline $\mathrm{Q}_{1}$ & $1.1(0.83-1.41)$ & $1.1(0.70-1.76)$ & $1.1(0.83-1.37)$ & $1.0(0.62-1.53)$ \\
\hline $\mathrm{Q}_{2-3}$ & 1 & 1 & 1 & 1 \\
\hline $\mathrm{Q}_{4}$ & $0.8(0.64-1.11)$ & $0.9(0.56-1.53)$ & $1.1(0.86-1.44)$ & $1.0(0.61-1.50)$ \\
\hline $\mathrm{p}$-value & 0.26 & 0.81 & 0.70 & 0.98 \\
\hline \multicolumn{5}{|l|}{ Sum of $18: 1$ isomers, $g$} \\
\hline $\mathrm{Q}_{1}$ & $1.1(0.83-1.41)$ & $1.1(0.71-1.79)$ & $1.1(0.87-1.43)$ & $1.0(0.66-1.60)$ \\
\hline $\mathrm{Q}_{2-3}$ & 1 & 1 & & 1 \\
\hline
\end{tabular}




\begin{tabular}{|c|c|c|c|c|}
\hline $\begin{array}{l}\mathrm{Q}_{4} \\
\mathrm{p} \text {-value }\end{array}$ & $\begin{array}{l}0.9(0.64-1.12) \\
0.29\end{array}$ & $\begin{array}{l}1.0(0.58-1.57) \\
0.87\end{array}$ & $\begin{array}{l}1.1(0.87-1.46) \\
0.56\end{array}$ & $\begin{array}{l}1.0(0.63-1.527 \\
0.74\end{array}$ \\
\hline \multicolumn{5}{|l|}{ PUFA, $\mathrm{g}$} \\
\hline $\mathrm{Q}_{1}$ & $1.2(0.94-1.60)$ & $1.7(1.07-2.69)$ & $1.1(0.86-1.42)$ & $1.4(0.94-2.22)$ \\
\hline $\mathrm{Q}_{2-3}$ & 1 & 1 & 1 & 1 \\
\hline $\mathrm{Q}_{4}$ & $0.9(0.70-1.22)$ & $1.2(0.73-1.94)$ & $1.0(0.75-1.25)$ & $1.1(0.71-1.76)$ \\
\hline $\mathrm{p}$-value & 0.19 & 0.13 & 0.62 & 0.31 \\
\hline \multicolumn{5}{|l|}{ n-3 PUFA, g } \\
\hline $\mathrm{Q}_{1}$ & $1.1(0.81-1.39)$ & $1.3(0.82-2.13)$ & $1.3(1.00-1.64)$ & $2.2(1.42-3.37)$ \\
\hline $\mathrm{Q}_{2-3}$ & 1 & 1 & 1 & 1 \\
\hline $\mathrm{Q}_{4}$ & $0.9(0.67-1.15)$ & $1.0(0.61-1.58)$ & $1.0(0.80-1.35)$ & $1.6(1.04-2.60)$ \\
\hline p-value & 0.46 & & & 0.003 \\
\hline \multicolumn{5}{|c|}{$\alpha$-Linolenic acid (18:3n-3), g } \\
\hline $\mathrm{Q}_{1}$ & $1.0(0.73-1.26)$ & $1.2(0.73-1.97)$ & $1.15(0.89-1.47)$ & $1.6(1.06-2.52)$ \\
\hline $\mathrm{Q}_{2-3}$ & 1 & 1 & 1 & 1 \\
\hline $\mathrm{Q}_{4}$ & $1.0(0.76-1.30)$ & $1.1(0.67-1.67)$ & $1.05(0.81-1.35)$ & $1.2(0.79-1.97)$ \\
\hline p-value & 0.96 & 0.57 & 0.57 & 0.10 \\
\hline \multicolumn{5}{|c|}{$\operatorname{EPA}(20: 5 n-3), \mathrm{mg}$} \\
\hline $\mathrm{Q}_{1}$ & $0.9(0.71-1.22)$ & $0.8(0.48-1.32)$ & $1.03(0.80-1.33)$ & $1.0(0.65-1.57)$ \\
\hline $\mathrm{Q}_{2-3}$ & 1 & 1 & 1 & 1 \\
\hline $\mathrm{Q}_{4}$ & $0.8(0.63-1.09)$ & $0.8(0.50-1.32)$ & $0.8(0.61-1.02)$ & $0.7(0.45-1.14)$ \\
\hline p-value & 0.37 & 0.56 & 0.11 & 0.27 \\
\hline \multicolumn{5}{|c|}{ DHA (22:6n-3), mg } \\
\hline $\mathrm{Q}_{1}$ & $1.0(0.76-1.33)$ & $0.9(0.53-1.46)$ & $1.05(0.82-1.35)$ & $1.0(0.65-1.55)$ \\
\hline $\mathrm{Q}_{2-3}$ & 1 & 1 & 1 & 1 \\
\hline $\mathrm{Q}_{4}$ & $0.9(0.70-1.21)$ & $0.8(0.51-1.34)$ & $0.8(0.62-1.04)$ & $0.7(0.43-1.11)$ \\
\hline $\mathrm{p}$-value & 0.80 & 0.71 & 0.13 & 0.22 \\
\hline \multicolumn{5}{|l|}{ n-6 PUFA, g } \\
\hline $\mathrm{Q}_{1}$ & $1.2(0.89-1.53)$ & $1.5(0.96-2.41)$ & $1.0(0.74-1.22)$ & $1.3(0.82-1.94)$ \\
\hline $\mathrm{Q}_{2-3}$ & 1 & 1 & 1 & 1 \\
\hline $\mathrm{Q}_{4}$ & $0.8(0.62-1.09)$ & $1.0(0.62-1.69)$ & $0.9(0.70-1.18)$ & $1.0(0.61-1.54)$ \\
\hline p-value & 0.10 & 0.24 & 0.76 & 0.54 \\
\hline \multicolumn{5}{|c|}{ Linoleic acid $(18: 2 n-6), \mathrm{g}$} \\
\hline $\mathrm{Q}_{1}$ & $1.2(0.94-1.60)$ & $1.7(1.05-2.64)$ & $1.0(0.75-1.23)$ & $1.3(0.84-1.99)$ \\
\hline $\mathrm{Q}_{2-3}$ & 1 & 1 & 1 & 1 \\
\hline $\mathrm{Q}_{4}$ & $0.9(0.67-1.17)$ & $1.1(0.67-1.81)$ & $0.9(0.71-1.19)$ & $1.0(0.64-1.62)$ \\
\hline $\mathrm{p}$-value & 0.13 & 0.14 & 0.81 & 0.52 \\
\hline \multicolumn{5}{|c|}{$\begin{array}{l}\text { Arachidonic acid }(20: 4 n-6) \text {, } \\
\mathrm{mg}\end{array}$} \\
\hline $\mathrm{Q}_{1}$ & $0.9(0.67-1.17)$ & $0.8(0.49-1.31)$ & $1.0(0.80-1.33)$ & $1.2(0.77-1.86)$ \\
\hline $\mathrm{Q}_{2-3}$ & 1 & 1 & 1 & 1 \\
\hline $\mathrm{Q}_{4}$ & $0.7(0.57-0.99)$ & $0.7(0.44-1.19)$ & $1.0(0.75-1.24)$ & $1.1(0.70-1.71)$ \\
\hline p-value & 0.10 & 0.37 & 0.91 & 0.74 \\
\hline \multicolumn{5}{|c|}{$\gamma$-Linoleic acid $(18: 3 n-6), \mathrm{mg}$} \\
\hline $\mathrm{Q}_{1}$ & $1.1(0.81-1.4)$ & $1.3(0.85-2.05)$ & $1.2(0.94-1.54)$ & $0.9(0.60-1.46)$ \\
\hline $\mathrm{Q}_{2-3}$ & 1 & 1 & 1 & 1 \\
\hline $\mathrm{Q}_{4}$ & $0.9(0.70-1.23)$ & $0.9(0.54-1.55)$ & $1.0(0.73-1.23)$ & $1.1(0.70-1.68)$ \\
\hline p-value & 0.70 & 0.39 & 0.23 & 0.86 \\
\hline \multicolumn{5}{|c|}{$\begin{array}{l}\text { Conjugated linoleic acid } \\
(18: 2 n-6), \mathrm{mg}\end{array}$} \\
\hline $\mathrm{Q}_{1}$ & $0.9(0.71-1.22)$ & $1.1(0.66-1.67)$ & $1.1(0.87-1.42)$ & $0.9(0.58-1.44)$ \\
\hline $\mathrm{Q}_{2-3}$ & 1 & 1 & 1 & 1 \\
\hline $\mathrm{Q}_{4}$ & $1.0(0.73-1.27)$ & $1.0(0.61-1.72)$ & $1.0(0.74-1.25)$ & $1.0(0.66-1.59)$ \\
\hline p-value & 0.87 & 0.98 & 0.57 & 0.89 \\
\hline
\end{tabular}

Trans fatty acids, $g$ 


\begin{tabular}{|c|c|c|c|c|}
\hline $\mathrm{Q}_{1}$ & $1.2(0.93-1.60)$ & $1.3(0.82-2.07)$ & $1.2(0.92-1.50)$ & $1.1(0.70-1.72)$ \\
\hline $\mathrm{Q}_{2-3}$ & 1 & 1 & 1 & 1 \\
\hline $\mathrm{Q}_{4}$ & $1.3(1.03-1.77)$ & $1.5(0.93-2.45)$ & $1.1(0.82-1.36)$ & $1.2(0.78-1.89)$ \\
\hline $\mathrm{p}$-value & 0.08 & 0.23 & 0.46 & 0.69 \\
\hline \\
\hline \multicolumn{5}{|l|}{$n-6: n-3$} \\
\hline $\mathrm{Q}_{1}$ & $0.9(0.66-1.13)$ & $0.8(0.47-1.22)$ & $1.3(1.05-1.71)$ & $1.9(1.20-2.85)$ \\
\hline $\mathrm{Q}_{2-3}$ & 1 & 1 & 1 & 1 \\
\hline $\mathrm{Q}_{4}$ & $1.0(0.76-1.32)$ & $1.1(0.70-1.82)$ & $1.2(0.89-1.50)$ & $1.8(1.12-2.81)$ \\
\hline $\mathrm{p}$-value & 0.52 & 0.32 & 0.07 & 0.008 \\
\hline \multicolumn{5}{|c|}{ Linoleic acid $(18: 2 n-6): \alpha-$} \\
\hline $\mathrm{Q}_{1}$ & $1.0(0.76-1.29)$ & $1.0(0.63-1.58)$ & $1.4(1.09-1.78)$ & $1.7(1.13-2.69)$ \\
\hline $\mathrm{Q}_{2-3}$ & 1 & 1 & 1 & 1 \\
\hline $\mathrm{Q}_{4}$ & $0.8(0.64-1.12)$ & $0.9(0.56-1.55)$ & $1.2(0.95-1.57)$ & $1.8(1.13-2.80)$ \\
\hline p-value & 0.44 & 0.96 & 0.03 & 0.01 \\
\hline \multicolumn{5}{|c|}{$\begin{array}{l}\text { Arachidonic acid (20:4n- } \\
6): \text { DHA+EPA }\end{array}$} \\
\hline $\mathrm{Q}_{1}$ & $0.9(0.65-1.12)$ & $0.7(0.47-1.19)$ & $0.9(0.69-1.13)$ & $0.8(0.54-1.31)$ \\
\hline $\mathrm{Q}_{2-3}$ & 1 & 1 & 1 & 1 \\
\hline $\mathrm{Q}_{4}$ & $0.9(0.70-1.21)$ & $0.7(0.41-1.14)$ & $0.9(0.73-1.22)$ & $0.9(0.54-1.40)$ \\
\hline p-value & 0.49 & 0.23 & 0.60 & 0.69 \\
\hline
\end{tabular}

The OR (95\% CI) are from generalized estimating equations. p-values are based on type 3 Score test. The fatty acid variables used in statistical analysis were energy-adjusted using Willett's residual method after logarithmic transformation. The sum of the 18:1 isomers consists mainly of oleic acid (18:1 n-9) and cis-vaccenic acid (18:1 n-7). IOTF = International Obesity Task Force; $\mathrm{E} \%=$ percent of daily energy intake; SFA = Saturated fatty acid; MUFA = Monounsaturated fatty acid; PUFA = Polyunsaturated fatty acid; DHA $=$ Docosahexaenoic acid; EPA = Eicosapentaenoic acid. $\mathrm{Q}_{1}=1^{\text {st }}$ quartile; $\mathrm{Q}_{2-3}=$ the 2 middle quartiles; $\mathrm{Q}_{4}=4^{\text {th }}$ quartile. 
Table S3. Adjusted odds ratios (OR) for offspring overweight (including obesity) and obesity based on IOTF criteria from the ages of 2 to 7 years according to tertiles of maternal energy and fatty acid intake during pregnancy in 3807 mother-child pairs, the DIPP Nutrition Study, Finland.

\begin{tabular}{|c|c|c|c|c|}
\hline & \multicolumn{2}{|c|}{ Boys $(n=1984)$} & \multicolumn{2}{|c|}{ Girls $(n=1823)$} \\
\hline & Overweight & Obesity & Overweight & Obesity \\
\hline & OR $(95 \% \mathrm{CI})$ & OR $(95 \% \mathrm{CI})$ & OR $(95 \% \mathrm{CI})$ & OR $(95 \% \mathrm{CI})$ \\
\hline \multicolumn{5}{|l|}{ Total energy intake, $\mathrm{kJ}$} \\
\hline $\mathrm{T}_{1}<10000$ & $1.2(0.89-1.60)$ & $1.0(0.56-1.61)$ & $1.1(0.83-1.46)$ & $1.3(0.81-2.10)$ \\
\hline $\mathrm{T}_{2} 10000-12450$ & 1 & 1 & 1 & 1 \\
\hline $\mathrm{T}_{3}>12450$ & $1.4(1.05-1.87)$ & $1.5(0.90-2.43)$ & $0.9(0.69-1.19)$ & $0.7(0.42-1.16)$ \\
\hline p-value & 0.07 & 0.24 & 0.37 & 0.048 \\
\hline \multicolumn{5}{|l|}{ Carbohydrates, E\% } \\
\hline $\mathrm{T}_{1}<48.4$ & $1.0(0.76-1.37)$ & $1.1(0.68-1.85)$ & $1.2(0.90-1.60)$ & $1.1(0.67-1.80)$ \\
\hline $\mathrm{T}_{2} 48.4-52.6$ & 1 & 1 & 1 & 1 \\
\hline $\mathrm{T}_{3}>52.6$ & $1.0(0.77-1.37)$ & $0.9(0.53-1.47)$ & $1.5(1.14-1.97)$ & $1.2(0.75-1.97)$ \\
\hline $\mathrm{p}$-value & 0.98 & 0.66 & 0.02 & 0.76 \\
\hline \multicolumn{5}{|l|}{ Proteins, E\% } \\
\hline $\mathrm{T}_{1}<15.1$ & $1.0(0.71-1.30)$ & $0.9(0.55-1.63)$ & $1.4(1.05-1.82)$ & $1.5(0.89-2.51)$ \\
\hline $\mathrm{T}_{2} 15.1-17.0$ & 1 & 1 & 1 & 1 \\
\hline $\mathrm{T}_{3}>17.0$ & $1.1(0.83-1.48)$ & $1.3(0.79-2.23)$ & $1.2(0.94-1.65)$ & $1.7(1.03-2.73)$ \\
\hline p-value & 0.64 & 0.44 & 0.06 & 0.08 \\
\hline \multicolumn{5}{|l|}{ Fats, E\% } \\
\hline $\mathrm{T}_{1}<31.1$ & $1.1(0.85-1.50)$ & $1.1(0.70-1.85)$ & $1.3(0.96-1.65)$ & $1.1(0.65-1.70)$ \\
\hline $\mathrm{T}_{2} 31.1-35.1$ & 1 & 1 & 1 & 1 \\
\hline $\mathrm{T}_{3}>35.1$ & $0.9(0.67-1.24)$ & $1.0(0.60-1.85)$ & $1.1(0.80-1.41)$ & $1.0(0.59-1.58)$ \\
\hline $\mathrm{p}$-value & 0.36 & 0.86 & 0.23 & 0.95 \\
\hline \multicolumn{5}{|l|}{ SFA, g } \\
\hline $\mathrm{T}_{1}$ & $1.0(0.78-1.39)$ & $1.1(0.66-1.87)$ & $1.2(0.90-1.54)$ & $0.8(0.51-1.31)$ \\
\hline $\mathrm{T}_{2}$ & 1 & 1 & 1 & 1 \\
\hline $\mathrm{T}_{3}$ & $0.9(0.70-1.28)$ & $1.1(0.66-1.98)$ & $1.0(0.75-1.36)$ & $0.8(0.49-1.36)$ \\
\hline $\mathrm{p}$-value & 0.81 & 0.88 & 0.43 & 0.65 \\
\hline \multicolumn{5}{|l|}{ Myristic acid (14:0), g } \\
\hline $\mathrm{T}_{1}$ & $0.9(0.68-1.22)$ & $0.8(0.47-1.29)$ & $1.1(0.82-1.41)$ & $0.9(0.57-1.52)$ \\
\hline $\mathrm{T}_{2}$ & 1 & 1 & 1 & 1 \\
\hline $\mathrm{T}_{3}$ & $1.0(0.76-1.38)$ & $1.0(0.62-1.75)$ & $1.0(0.78-1.38)$ & $1.1(0.65-1.71)$ \\
\hline p-value & 0.71 & 0.46 & 0.86 & 0.91 \\
\hline \multicolumn{5}{|l|}{ Palmitic acid (16:0), g } \\
\hline $\mathrm{T}_{1}$ & $1.1(0.85-1.53)$ & $1.3(0.77-2.29)$ & $1.2(0.92-1.58)$ & $0.9(0.58-1.51)$ \\
\hline $\mathrm{T}_{2}$ & 1 & 1 & 1 & 1 \\
\hline $\mathrm{T}_{3}$ & $1.0(0.74-1.36)$ & $1.4(0.82-2.52)$ & $1.1(0.80-1.43)$ & $1.0(0.60-1.61)$ \\
\hline p-value & 0.59 & 0.38 & 0.42 & 0.96 \\
\hline \multicolumn{5}{|l|}{ Stearic acid (18:0), mg } \\
\hline $\mathrm{T}_{1}$ & $1.6(0.87-1.54)$ & $1.3(0.79-2.24)$ & $1.2(0.90-1.57)$ & $1.0(0.59-1.57)$ \\
\hline $\mathrm{T}_{2}$ & 1 & 1 & 1 & 1 \\
\hline $\mathrm{T}_{3}$ & $0.9(0.67-1.23)$ & $1.2(0.71-2.12)$ & $1.0(0.77-1.37)$ & $0.9(0.56-1.51)$ \\
\hline $\mathrm{p}$-value & 0.28 & 0.53 & 0.45 & 0.94 \\
\hline \multicolumn{5}{|l|}{ MUFA, g } \\
\hline $\mathrm{T}_{1}$ & $1.0(0.76-1.34)$ & $1.1(0.64-1.73)$ & $1.0(0.75-1.30)$ & $0.9(0.53-1.38)$ \\
\hline $\mathrm{T}_{2}$ & 1 & 1 & 1 & 1 \\
\hline $\mathrm{T}_{3}$ & $0.8(0.61-1.12)$ & $1.0(0.56-1.65)$ & $1.0(0.74-1.29)$ & $1.0(0.59-1.57)$ \\
\hline p-value & 0.35 & 0.95 & 0.99 & 0.80 \\
\hline \multicolumn{5}{|l|}{ Sum of $18: 1$ isomers, $\mathrm{g}$} \\
\hline $\mathrm{T}_{1}$ & $0.9(0.71-1.25)$ & $1.0(0.62-1.68)$ & $1.0(0.79-1.35)$ & $1.0(0.59-1.55)$ \\
\hline $\mathrm{T}_{2}$ & 1 & 1 & 1 & 1 \\
\hline
\end{tabular}




\begin{tabular}{|c|c|c|c|c|}
\hline $\begin{array}{l}T_{3} \\
p \text {-value }\end{array}$ & $\begin{array}{l}0.8(0.58-1.06) \\
0.25\end{array}$ & $\begin{array}{l}0.9(0.56-1.61) \\
0.96\end{array}$ & $\begin{array}{l}1.0(0.78-1.36) \\
0.97\end{array}$ & $\begin{array}{l}1.1(0.65-1.73) \\
0.93\end{array}$ \\
\hline \multicolumn{5}{|l|}{ PUFA, $g$} \\
\hline $\mathrm{T}_{1}$ & $1.2(0.90-1.59)$ & $1.4(0.87-2.40)$ & $1.2(0.88-1.52)$ & $1.18(0.72-1.92)$ \\
\hline $\mathrm{T}_{2}$ & 1 & 1 & 1 & 1 \\
\hline $\mathrm{T}_{3}$ & $0.9(0.68-1.23)$ & $1.1(0.65-1.89)$ & $1.0(0.79-1.37)$ & $1.1(0.66-1.86)$ \\
\hline p-value & 0.20 & 0.38 & & \\
\hline \multicolumn{5}{|l|}{ n-3 PUFA, g } \\
\hline $\mathrm{T}_{1}$ & $1.1(0.83-1.50)$ & $1.5(0.87-2.50)$ & $1.1(0.81-1.40)$ & $1.3(0.80-2.07)$ \\
\hline $\mathrm{T}_{2}$ & 1 & 1 & 1 & 1 \\
\hline $\mathrm{T}_{3}$ & $0.9(0.69-1.26)$ & $1.2(0.68-1.98)$ & $1.0(0.79-1.38)$ & $1.2(0.73-2.01)$ \\
\hline $\mathrm{p}$-value & 0.47 & 0.36 & 0.89 & 0.56 \\
\hline \multicolumn{5}{|c|}{$\alpha$-Linolenic acid (18:3n-3), g } \\
\hline $\mathrm{T}_{1}$ & $1.1(0.80-1.41)$ & $1.4(0.82-2.28)$ & $1.0(0.79-1.36)$ & $1.4(0.88-2.35)$ \\
\hline $\mathrm{T}_{2}$ & 1 & 1 & 1 & 1 \\
\hline $\mathrm{T}_{3}$ & $1.0(0.74-1.33)$ & $1.1(0.65-1.81)$ & $1.0(0.78-1.35)$ & $1.3(0.81-2.23)$ \\
\hline $\mathrm{p}$-value & 0.89 & 0.49 & 0.97 & 0.29 \\
\hline \multicolumn{5}{|c|}{$\operatorname{EPA}(20: 5 n-3), \mathrm{mg}$} \\
\hline $\mathrm{T}_{1}$ & $0.9(0.69-1.24)$ & $0.7(0.38-1.12)$ & $1.0(0.78-1.36)$ & $0.9(0.54-1.38)$ \\
\hline $\mathrm{T}_{2}$ & 1 & 1 & 1 & 1 \\
\hline $\mathrm{T}_{3}$ & $1.0(0.74-1.34)$ & $1.0(0.63-1.69)$ & $0.9(0.68-1.19)$ & $0.7(0.41-1.13)$ \\
\hline p-value & 0.84 & 0.16 & 0.59 & 0.35 \\
\hline \multicolumn{5}{|c|}{ DHA $(22: 6 n-3), m g$} \\
\hline $\mathrm{T}_{1}$ & $0.8(0.63-1.13)$ & $0.5(0.29-0.89)$ & $\begin{array}{l}1.1610 .881 \\
1.532\end{array}$ & $1.1(0.69-1.82)$ \\
\hline $\mathrm{T}_{2}$ & 1 & 1 & 1 & 1 \\
\hline $\mathrm{T}_{3}$ & $0.9(0.71-1.27)$ & $1.0(0.60-1.58)$ & $1.0(0.77-1.34)$ & $1.0(0.59-1.63)$ \\
\hline p-value & 0.49 & 0.02 & 0.52 & 0.85 \\
\hline \multicolumn{5}{|l|}{ n-6 PUFA, g } \\
\hline $\mathrm{T}_{1}$ & $1.1(0.84-1.49)$ & $1.5(0.91-2.53)$ & $1.0(0.74-1.27)$ & $0.9(0.56-1.49)$ \\
\hline $\mathrm{T}_{2}$ & 1 & 1 & 1 & 1 \\
\hline $\mathrm{T}_{3}$ & $0.8(0.63-1.14)$ & $1.1(0.66-1.94)$ & $0.9(0.69-1.21)$ & $0.8(0.50-1.37)$ \\
\hline p-value & 0.17 & 0.31 & 0.81 & 0.75 \\
\hline \multicolumn{5}{|c|}{ Linoleic acid (18:2n-6), g } \\
\hline $\mathrm{T}_{1}$ & $1.1(0.85-1.50)$ & $1.4(0.85-2.37)$ & $1.0(0.78-1.35)$ & $1.1(0.65-1.70)$ \\
\hline $\mathrm{T}_{2}$ & 1 & 1 & 1 & 1 \\
\hline $\mathrm{T}_{3}$ & $0.8(0.62-1.13)$ & $1.0(0.60-1.75)$ & $0.9(0.69-1.21)$ & $0.9(0.53-1.46)$ \\
\hline $\mathrm{p}$-value & 0.13 & 0.38 & 0.70 & 0.74 \\
\hline \multicolumn{5}{|c|}{$\begin{array}{l}\text { Arachidonic acid }(20: 4 n-6) \text {, } \\
\text { mg }\end{array}$} \\
\hline $\mathrm{T}_{1}$ & $0.9(0.65-1.15)$ & $0.7(0.43-1.20)$ & $1.0(0.73-1.25)$ & $1.0(0.60-1.59$ \\
\hline $\mathrm{T}_{2}$ & 1 & 1 & 1 & 1 \\
\hline $\mathrm{T}_{3}$ & $0.7(0.52-0.93)$ & $0.6(0.36-1.03)$ & $0.8(0.61-1.05)$ & $0.9(0.53-1.38)$ \\
\hline p-value & 0.046 & 0.15 & 0.25 & 0.80 \\
\hline \multicolumn{5}{|c|}{$\gamma$-Linoleic acid (18:3n-6), mg } \\
\hline $\mathrm{T}_{1}$ & $1.2(0.88-1.59)$ & $1.5(0.88-2.46)$ & $1.1(0.86-1.49)$ & $0.8(0.50-1.33)$ \\
\hline $\mathrm{T}_{2}$ & 1 & 1 & 1 & 1 \\
\hline $\mathrm{T}_{3}$ & $1.3(0.94-1.73)$ & $1.6(0.91-2.81)$ & $1.1(0.85-1.49)$ & $1.2(0.73-1.94)$ \\
\hline p-value & 0.27 & 0.18 & 0.60 & 0.37 \\
\hline \multicolumn{5}{|c|}{$\begin{array}{l}\text { Conjugated linoleic acid } \\
(18: 2 n-6), \mathrm{mg}\end{array}$} \\
\hline $\mathrm{T}_{1}$ & $0.9(0.70-1.25)$ & $0.7(0.46-1.18)$ & $1.1(0.86-1.47)$ & $1.2(0.70-1.95)$ \\
\hline $\mathrm{T}_{2}$ & 1 & 1 & 1 & 1 \\
\hline $\mathrm{T}_{3}$ & $1.1(0.82-1.48)$ & $1.0(0.58-1.65)$ & $1.2(0.89-1.54)$ & $1.6(0.99-2.67)$ \\
\hline p-value & 0.55 & 0.38 & 0.54 & 0.16 \\
\hline
\end{tabular}




\begin{tabular}{|c|c|c|c|c|}
\hline \multicolumn{5}{|l|}{ Trans fatty acids, $g$} \\
\hline $\mathrm{Q}_{1} 0.9$ & $1.2(0.88-1.59)$ & $1.0(0.63-1.69)$ & $1.1(0.80-1.39)$ & $0.8(0.50-1.36)$ \\
\hline $\mathrm{Q}_{2-3} 0.9-1.6$ & 1 & 1 & 1 & 1 \\
\hline $\mathrm{Q}_{4} 1.6$ & $1.4(1.07-1.95)$ & $1.4(0.83-2.40)$ & $1.1(0.84-1.45)$ & $1.0(0.63-1.64)$ \\
\hline $\mathrm{p}$-value & 0.06 & 0.43 & 0.77 & 0.68 \\
\hline \multicolumn{5}{|l|}{ Ratios } \\
\hline \multicolumn{5}{|l|}{$n-6: n-3$} \\
\hline $\mathrm{T}_{1}$ & $1.2(0.87-1.54)$ & $1.0(0.63-1.67)$ & $1.3(1.02-1.76)$ & $2.5(1.45-4.19)$ \\
\hline $\mathrm{T}_{2}$ & 1 & 1 & 1 & 1 \\
\hline $\mathrm{T}_{3}$ & $0.9(0.67-1.23)$ & $0.9(0.50-1.55)$ & $1.3(1.01-1.74)$ & $2.2(1.32-3.78)$ \\
\hline $\mathrm{p}$-value & 0.27 & 0.86 & 0.047 & 0.0006 \\
\hline \multirow{2}{*}{\multicolumn{5}{|c|}{$\begin{array}{l}\text { Linoleic acid }(18: 2 n-6): \alpha- \\
\text { Linolenic acid }(18: 3 n-3)\end{array}$}} \\
\hline & & & & \\
\hline $\mathrm{T}_{1}$ & $1.2(0.91-1.63)$ & $1.0(0.59-1.61)$ & $1.1(0.84-1.44)$ & $1.2(0.77-1.98)$ \\
\hline $\mathrm{T}_{2}$ & 1 & 1 & 1 & 1 \\
\hline $\mathrm{T}_{3}$ & $1.0(0.72-1.31)$ & $1.0(0.61-1.79)$ & $1.0(0.77-1.33)$ & $1.2(0.72-1.92)$ \\
\hline p-value & 0.25 & 0.97 & 0.73 & 0.66 \\
\hline \multicolumn{5}{|c|}{$\begin{array}{l}\text { Arachidonic acid (20:4n- } \\
\text { 6):DHA+EPA }\end{array}$} \\
\hline $\mathrm{T}_{1}$ & $1.1(0.80-1.42)$ & $1.2(0.75-1.91)$ & $1.3(0.95-1.68)$ & $1.5(0.87-2.43)$ \\
\hline $\mathrm{T}_{2}$ & 1 & 1 & 1 & 1 \\
\hline $\mathrm{T}_{3}$ & $0.8(0.60-1.10)$ & $0.6(0.32-1.02)$ & $1.2(0.90-1.56)$ & $1.2(0.761 .98)$ \\
\hline $\mathrm{p}$-value & 0.20 & 0.04 & 0.23 & 0.36 \\
\hline
\end{tabular}

The OR $(95 \% \mathrm{CI})$ are from generalized estimating equations adjusted for maternal early pregnancy BMI, gestational weight gain rate, time of the first weight measurement $(\leq 10.0$ vs $>10$ weeks of pregnancy) glucose intolerance diet, education, smoking during pregnancy, and duration of breastfeeding. p-values are based on type 3 Score test. The fatty acid variables used in statistical analysis were energy-adjusted using Willett's residual method after logarithmic transformation. The sum of the 18:1 isomers consists mainly of oleic acid (18:1 n-9) and cis-vaccenic acid (18:1 n-7). $\mathrm{IOTF}=$ International Obesity Task Force; E\% = percent of daily energy intake; SFA = Saturated fatty acid; MUFA = Monounsaturated fatty acid; PUFA = Polyunsaturated fatty acid; DHA = Docosahexaenoic acid $\mathrm{EPA}=$ Eicosapentaenoic acid; $\mathrm{T}_{1}=1^{\text {st }}$ tertile; $\mathrm{T}_{2}=2^{\text {nd }}$ tertile; $\mathrm{T}_{3}=3^{\text {rd }}$ tertile . 
Table S4. Adjusted odds ratios (OR) for offspring overweight (including obesity) and obesity based on WHO criteria from the ages of 2 to 7 years according to quartiles of maternal energy and fatty acid intake during pregnancy in 3807 mother-child pairs, the DIPP Nutrition Study, Finland.

\begin{tabular}{|c|c|c|c|c|}
\hline & \multicolumn{2}{|c|}{ Boys $(n=1984)$} & \multicolumn{2}{|c|}{ Girls $(n=1823)$} \\
\hline & Overweight & Obesity & Overweight & Obesity \\
\hline & OR $(95 \% \mathrm{CI})$ & OR $(95 \% \mathrm{CI})$ & OR $(95 \% \mathrm{CI})$ & OR $(95 \% \mathrm{CI})$ \\
\hline \multicolumn{5}{|l|}{ Total energy intake, $\mathrm{kJ}$} \\
\hline $\mathrm{Q}_{1}<9300$ & $0.9(0.76-1.16)$ & $1.3(0.93-1.87)$ & $1.1(0.88-1.34)$ & $1.2(0.81-1.70)$ \\
\hline $\mathrm{Q}_{2-3} 9300-13400$ & 1 & 1 & 1 & 1 \\
\hline $\mathrm{Q}_{4}>13400$ & $1.2(0.97-1.44)$ & $1.5(1.07-2.13)$ & $1.1(0.90-1.33)$ & $0.9(0.66-1.29)$ \\
\hline $\mathrm{p}$-value & 0.15 & 0.06 & 0.58 & 0.52 \\
\hline \multicolumn{5}{|l|}{ Carbohydrates, E\% } \\
\hline $\mathrm{Q}_{1}<47.2$ & $0.9(0.70-1.05)$ & $0.8(0.58-1.20)$ & $1.1(0.88-1.32)$ & $1.1(0.76-1.56)$ \\
\hline $\mathrm{Q}_{2-3} 47.2-53.8$ & 1 & 1 & 1 & 1 \\
\hline $\mathrm{Q}_{4}>53.8$ & $0.9(0.78-1.15)$ & $1.0(0.68-1.38)$ & $1.1(0.87-1.31)$ & $1.2(0.86-1.71)$ \\
\hline p-value & 0.32 & 0.59 & 0.70 & 0.55 \\
\hline \multicolumn{5}{|l|}{ Proteins, E\% } \\
\hline $\mathrm{Q}_{1}<14.7$ & $1.0(0.81-1.22)$ & $0.9(0.62-1.32)$ & $1.4(1.17-1.74)$ & $1.5(1.05-2.13)$ \\
\hline $\mathrm{Q}_{2-3} 14.7-17.5$ & 1 & 1 & 1 & 1 \\
\hline $\mathrm{Q}_{4}>17.5$ & $1.0(0.81-1.21)$ & $1.1(0.78-1.56)$ & $1.1(0.94-1.41)$ & $1.3(0.89-1.78)$ \\
\hline p-value & 0.99 & 0.65 & 0.003 & 0.09 \\
\hline \multicolumn{5}{|l|}{ Fats, E\% } \\
\hline $\mathrm{Q}_{1}<30.0$ & $1.1(0.88-1.30)$ & $1.0(0.71-1.38)$ & $1.0(0.78-1.17)$ & $0.8(0.59-1.17)$ \\
\hline $\mathrm{Q}_{2-3} 30.0-36.4$ & 1 & 1 & 1 & 1 \\
\hline $\mathrm{Q}_{4}>36.4$ & $1.0(0.78-1.17)$ & $0.9(0.60-1.25)$ & $1.1(0.92-1.38)$ & $0.9(0.63-1.34)$ \\
\hline p-value & 0.63 & 0.71 & & 0.55 \\
\hline \multicolumn{5}{|l|}{ SFA, $g$} \\
\hline $\mathrm{Q}_{1}$ & $1.0(0.87-1.27)$ & $0.9(0.68-1.32)$ & $1.0(0.79-1.19)$ & $0.8(0.58-1.15)$ \\
\hline $\mathrm{Q}_{2-3}$ & 1 & 1 & 1 & 1 \\
\hline $\mathrm{Q}_{4}$ & $1.0(0.82-1.24)$ & $0.8(0.58-1.21)$ & $1.1(0.87-1.30)$ & $1.0(0.66-1.38)$ \\
\hline p-value & 0.88 & 0.63 & 0.74 & 0.50 \\
\hline \multicolumn{5}{|l|}{ Myristic acid (14:0), g } \\
\hline $\mathrm{Q}_{1}$ & $0.9(0.74-1.10)$ & $0.8(0.60-1.19)$ & $1.0(0.82-1.23)$ & $1.0(0.71-1.41)$ \\
\hline $\mathrm{Q}_{2-3}$ & 1 & 1 & 1 & 1 \\
\hline $\mathrm{Q}_{4}$ & $1.0(0.80-1.20)$ & $0.9(0.65-1.34)$ & $1.0(0.81-1.22)$ & $1.0(0.72-1.53)$ \\
\hline $\mathrm{p}$-value & 0.59 & 0.62 & 0.99 & 0.97 \\
\hline \multicolumn{5}{|l|}{ Palmitic acid (16:0), g } \\
\hline $\mathrm{Q}_{1}$ & $1.0(0.87-1.28)$ & $1.0(0.73-1.41)$ & $1.0(0.79-1.19)$ & $0.8(0.54-1.09)$ \\
\hline $\mathrm{Q}_{2-3}$ & 1 & 1 & 1 & 1 \\
\hline $\mathrm{Q}_{4}$ & $0.9(0.74-1.12)$ & $0.9(0.60-1.24)$ & $1.1(0.89-1.33)$ & $1.0(0.67-1.39)$ \\
\hline p-value & 0.43 & 0.67 & 0.60 & 0.30 \\
\hline \multicolumn{5}{|l|}{ Stearic acid (18:0), mg } \\
\hline $\mathrm{Q}_{1}$ & $1.2(0.96-1.42)$ & $1.3(0.91-1.78)$ & $1.1(0.88-1.33)$ & $0.9(0.67-1.32)$ \\
\hline $\mathrm{Q}_{2-3}$ & 1 & 1 & 1 & 1 \\
\hline $\mathrm{Q}_{4}$ & $0.9(0.74-1.13)$ & $0.9(0.62-1.29)$ & $1.2(0.95-1.43)$ & $0.9(0.64-1.35)$ \\
\hline $\mathrm{p}$-value & 0.12 & 0.23 & 0.32 & 0.90 \\
\hline \multicolumn{5}{|l|}{ MUFA, g } \\
\hline $\mathrm{Q}_{1}$ & $1.2(0.95-1.41)$ & $1.1(0.75-1.48)$ & $1.0(0.80-1.20)$ & $0.9(0.66-1.30)$ \\
\hline $\mathrm{Q}_{2-3}$ & 1 & 1 & 1 & 1 \\
\hline $\mathrm{Q}_{4}$ & $1.0(0.85-1.27)$ & $0.8(0.59-1.20)$ & $1.2(0.96-1.44)$ & $0.9(0.64-1.38)$ \\
\hline p-value & 0.37 & 0.49 & 0.24 & 0.89 \\
\hline \multicolumn{5}{|l|}{ Sum of $18: 1$ isomers, $\mathrm{g}$} \\
\hline $\mathrm{Q}_{1}$ & $1.1(0.94-1.39)$ & $1.1(0.79-1.54)$ & $1.0(0.82-1.24)$ & $0.9(0.62-1.25)$ \\
\hline $\mathrm{Q}_{2-3}$ & 1 & 1 & 1 & 1 \\
\hline
\end{tabular}




\begin{tabular}{|c|c|c|c|c|}
\hline $\begin{array}{l}\mathrm{Q}_{4} \\
\mathrm{p} \text {-value }\end{array}$ & $\begin{array}{l}1.0(0.83-1.24) \\
0.41\end{array}$ & $\begin{array}{l}0.8(0.58-1.19) \\
0.38\end{array}$ & $\begin{array}{l}1.2(0.99-1.48) \\
0.17\end{array}$ & $\begin{array}{l}0.9(0.63-1.35) \\
0.75\end{array}$ \\
\hline \multicolumn{5}{|l|}{ PUFA, $\mathrm{g}$} \\
\hline $\mathrm{Q}_{1}$ & $1.1(0.89-1.33)$ & $1.1(0.79-1.60)$ & $1.0(0.83-1.24)$ & $1.1(0.76-1.51)$ \\
\hline $\mathrm{Q}_{2-3}$ & 1 & 1 & 1 & 1 \\
\hline $\mathrm{Q}_{4}$ & $0.9(0.73-1.10)$ & $0.9(0.64-1.33)$ & $1.0(0.81-1.22)$ & $0.9(0.61-1.30)$ \\
\hline $\mathrm{p}$-value & 0.28 & 0.65 & 0.99 & 0.68 \\
\hline \multicolumn{5}{|l|}{$n-3$ PUFA, g } \\
\hline $\mathrm{Q}_{1}$ & $1.0(0.80-1.20)$ & $0.9(0.65-1.34)$ & $1.0(0.85-1.27)$ & $1.5(1.05-2.03)$ \\
\hline $\mathrm{Q}_{2-3}$ & 1 & 1 & 1 & 1 \\
\hline $\mathrm{Q}_{4}$ & $0.9(0.75-1.13)$ & $0.9(0.60-1.23)$ & $1.0(0.82-1.24)$ & $1.3(0.89-1.85)$ \\
\hline p-value & 0.72 & 0.71 & 0.92 & 0.08 \\
\hline \multicolumn{5}{|c|}{$\begin{array}{l}\alpha \text {-Linolenic acid (18:3n- } \\
3 \text { ), g }\end{array}$} \\
\hline $\mathrm{Q}_{1}$ & $1.1(0.90-1.32)$ & $0.9(0.65-1.35)$ & $1.0(0.80-1.20)$ & $1.2(0.85-1.69)$ \\
\hline $\mathrm{Q}_{2-3}$ & 1 & 1 & 1 & 1 \\
\hline $\mathrm{Q}_{4}$ & $1.0(0.84-1.27)$ & $1.0(0.68-1.38)$ & $1.0(0.84-1.27)$ & $1.0(0.68-1.43)$ \\
\hline p-value & 0.75 & 0.94 & 0.90 & 0.54 \\
\hline \multicolumn{5}{|c|}{ EPA $(20: 5 n-3), \mathrm{mg}$} \\
\hline $\mathrm{Q}_{1}$ & $0.9(0.74-1.12)$ & $0.7(0.45-0.96)$ & $1.0(0.84-1.26)$ & $0.9(0.65-1.30)$ \\
\hline $\mathrm{Q}_{2-3}$ & 1 & 1 & 1 & 1 \\
\hline $\mathrm{Q}_{4}$ & $1.0(0.82-1.23)$ & $1.0(0.67-1.35)$ & $0.9(0.75-1.12)$ & $0.8(0.56-1.16)$ \\
\hline $\mathrm{p}$-value & 0.63 & 0.06 & 0.61 & 0.50 \\
\hline \multicolumn{5}{|c|}{ DHA $(22: 6 n-3), \mathrm{mg}$} \\
\hline $\mathrm{Q}_{1}$ & $0.9(0.77-1.17)$ & $0.7(0.45-0.97)$ & $1.0(0.85-1.27)$ & $1.0(0.67-1.35)$ \\
\hline $\mathrm{Q}_{2-3}$ & 1 & 1 & 1 & 1 \\
\hline $\mathrm{Q}_{4}$ & $1.1(0.87-1.29)$ & $1.0(0.72-1.42)$ & $0.9(0.73-1.10)$ & $0.8(0.59-1.21)$ \\
\hline $\mathrm{p}$-value & 0.68 & 0.06 & 0.47 & 0.64 \\
\hline \multicolumn{5}{|l|}{$n-6$ PUFA, g } \\
\hline $\mathrm{Q}_{1}$ & $1.1(0.92-1.38)$ & $1.1(0.79-1.59)$ & $0.9(0.75-1.13)$ & $1.0(0.69-1.37)$ \\
\hline $\mathrm{Q}_{2-3}$ & 1 & 1 & 1 & 1 \\
\hline $\mathrm{Q}_{4}$ & $0.9(0.72-1.07)$ & $0.8(0.53-1.11)$ & $0.9(0.7-1.16)$ & $0.8(0.53-1.12)$ \\
\hline p-value & 0.10 & 0.17 & 0.69 & 0.35 \\
\hline \multicolumn{5}{|c|}{ Linoleic acid (18:2n-6), g } \\
\hline $\mathrm{Q}_{1}$ & $1.1(0.94-1.40)$ & $1.2(0.81-1.63)$ & $1.0(0.79-1.18)$ & $1.0(0.70-1.41)$ \\
\hline $\mathrm{Q}_{2-3}$ & 1 & 1 & 1 & 1 \\
\hline $\mathrm{Q}_{4}$ & $0.9(0.74-1.10)$ & $0.8(0.56-1.16)$ & $1.0(0.80-1.20)$ & $0.8(0.57-1.21)$ \\
\hline p-value & 0.13 & 0.23 & 0.94 & 0.58 \\
\hline \multicolumn{5}{|c|}{$\begin{array}{l}\text { Arachidonic acid (20:4n- } \\
6), \mathrm{mg}\end{array}$} \\
\hline $\mathrm{Q}_{1}$ & $1.0(0.83-1.25)$ & $0.8(0.53-1.16)$ & $0.9(0.75-1.13)$ & $1.1(0.74-1.52)$ \\
\hline $\mathrm{Q}_{2-3}$ & 1 & 1 & 1 & 1 \\
\hline $\mathrm{Q}_{4}$ & $0.8(0.68-1.01)$ & $0.8(0.57-1.12)$ & $0.9(0.74-1.10)$ & $1.1(0.75-1.50)$ \\
\hline p-value & 0.12 & 0.28 & 0.53 & 0.92 \\
\hline \multicolumn{5}{|c|}{$\begin{array}{l}\gamma \text {-Linoleic acid }(18: 3 n-6), \\
\mathrm{mg}\end{array}$} \\
\hline $\mathrm{Q}_{1}$ & $0.9(0.74-1.09)$ & $0.9(0.67-1.30)$ & $1.0(0.80-1.20)$ & $0.9(0.66-1.32)$ \\
\hline $\mathrm{Q}_{2-3}$ & 1 & 1 & 1 & 1 \\
\hline $\mathrm{Q}_{4}$ & $0.9(0.72-1.09)$ & $0.7(0.49-1.05)$ & $1.0(0.81-1.21)$ & $1.0(0.72-1.51)$ \\
\hline p-value & 0.38 & 0.20 & 0.98 & 0.86 \\
\hline \multicolumn{5}{|c|}{$\begin{array}{l}\text { Conjugated linoleic acid } \\
(18: 2 n-6), \mathrm{mg}\end{array}$} \\
\hline $\mathrm{Q}_{1}$ & $0.9(0.71-1.06)$ & $0.7(0.49-1.00)$ & $1.1(0.86-1.29)$ & $0.8(0.57-1.14)$ \\
\hline $\mathrm{Q}_{2-3}$ & 1 & 1 & 1 & 1 \\
\hline $\mathrm{Q}_{4}$ & $1.0(0.78-1.18)$ & $0.8(0.54-1.14)$ & $1.0(0.85-1.28)$ & $0.9(0.63-1.34)$ \\
\hline
\end{tabular}




\begin{tabular}{|c|c|c|c|c|}
\hline $\mathrm{p}$-value & 0.36 & 0.10 & 0.86 & 0.47 \\
\hline \multicolumn{5}{|c|}{ Trans fatty acids, $\mathrm{g}$} \\
\hline $\mathrm{Q}_{1}$ & $1.0(0.84-1.24)$ & $1.1(0.75-1.51)$ & $1.0(0.78-1.18)$ & $1.0(0.74-1.48)$ \\
\hline $\mathrm{Q}_{2-3}$ & 1 & 1 & 1 & 1 \\
\hline $\mathrm{Q}_{4}$ & $1.2(0.95-1.43)$ & $1.2(0.87-1.77)$ & $1.0(0.83-1.23)$ & $1.0(0.72-1.51)$ \\
\hline $\mathrm{p}$-value & 0.34 & 0.52 & 0.90 & 0.96 \\
\hline \multicolumn{5}{|l|}{ Ratios } \\
\hline \multicolumn{5}{|l|}{$n-6: n-3$} \\
\hline $\mathrm{Q}_{1}$ & $1.1(0.88-1.29)$ & $0.9(0.64-1.24)$ & $1.2(0.96-1.45)$ & $1.6(1.14-2.27)$ \\
\hline $\mathrm{Q}_{2-3}$ & 1 & 1 & 1 & 1 \\
\hline $\mathrm{Q}_{4}$ & $1.0(0.78-1.18)$ & $0.9(0.66-1.37)$ & $1.0(0.83-1.23)$ & $1.4(1.00-2.02)$ \\
\hline p-value & 0.69 & 0.78 & 0.27 & 0.02 \\
\hline \multicolumn{5}{|c|}{$\begin{array}{l}\text { Linoleic acid }(18: 2 n-6): \alpha- \\
\text { Linolenic acid }(18 \cdot 3 n-3)\end{array}$} \\
\hline $\mathrm{Q}_{1}$ & $1.1(0.88-1.31)$ & $1.0(0.70-1.39)$ & $1.3(1.06-1.59)$ & $1.4(1.01-2.03)$ \\
\hline $\mathrm{Q}_{2-3}$ & 1 & 1 & 1 & 1 \\
\hline $\mathrm{Q}_{4}$ & $1.0(0.81-1.21)$ & $0.9(0.60-1.24)$ & $1.1(0.87-1.30)$ & $1.4(0.99-2.00)$ \\
\hline p-value & 0.76 & 0.70 & 0.048 & 0.07 \\
\hline \multicolumn{5}{|c|}{$\begin{array}{l}\text { Arachidonic acid (20:4n- } \\
\text { 6):DHA+EPA }\end{array}$} \\
\hline $\mathrm{Q}_{1}$ & $1.1(0.89-1.32)$ & $1.1(0.75-1.51)$ & $0.9(0.77-1.16)$ & $0.9(0.64-1.31)$ \\
\hline $\mathrm{Q}_{2-3}$ & 1 & 1 & 1 & 1 \\
\hline $\mathrm{Q}_{4}$ & $0.9(0.71-1.07)$ & $0.7(0.45-0.96)$ & $1.0(0.78-1.18)$ & $0.7(0.51-1.06)$ \\
\hline $\mathrm{p}$-value & 0.20 & 0.04 & 0.82 & 0.23 \\
\hline
\end{tabular}

The OR $(95 \% \mathrm{CI})$ are from generalized estimating equations adjusted for maternal early pregnancy BMI, gestational weight gain rate, time of the first weight measurement $(\leq 10.0 \mathrm{vs}>10$ weeks of pregnancy) glucose intolerance diet, education, smoking during pregnancy, and duration of breastfeeding. p-values are based on type 3 Score test. The fatty acid variables used in statistical analysis were energy-adjusted using Willett's residual method after logarithmic transformation. The sum of the 18:1 isomers consists mainly of oleic acid (18:1 n-9) and cis-vaccenic acid (18:1 n-7). $\mathrm{WHO}=$ World Health Organization; E\% = percent of daily energy intake; SFA = Saturated fatty acid; MUFA = Monounsaturated fatty acid; PUFA = Polyunsaturated fatty acid; DHA = Docosahexaenoic acid; EPA $=$ Eicosapentaenoic acid. $\mathrm{Q}_{1}=1^{\text {st }}$ quartile; $\mathrm{Q}_{2-3}=$ the 2 middle quartiles; $\mathrm{Q}_{4}=4^{\text {th }}$ quartile. 